Article

\title{
Preliminary Evaluation of the Error Budgets in the TALIS Measurements and Their Impact on the Retrievals
}

\author{
Wenyu Wang ${ }^{1,2} \mathbb{D}$, Zhenzhan Wang ${ }^{1, * \mathbb{C}}$ and Yongqiang Duan ${ }^{1,2}$ \\ 1 Key Laboratory of Microwave Remote Sensing, National Space Science Center, Chinese Academy of Sciences, \\ Beijing 100190, China; wangwenyu14@mails.ucas.ac.cn (W.W.); duanyongqiang15@mails.ucas.ac.cn (Y.D.) \\ 2 University of Chinese Academy of Sciences, Beijing 100094, China \\ * Correspondence: wangzhenzhan@mirslab.cn; Tel.: +86-10-6258-6454
}

Received: 10 December 2019; Accepted: 29 January 2020; Published: 2 February 2020

check for updates

\begin{abstract}
The THz Atmospheric Limb Sounder (TALIS) is a Chinese sub-millimeter limb sounder being designed by National Space Science Center of the Chinese Academy of Sciences to measure the temperature and chemical constituents vertically in the middle and upper atmosphere, with good precision and vertical resolution. This paper presents a simulation study that assesses the measurement errors and their impacts on the retrievals. Three error sources, including instrument uncertainties, calibration errors and a priori errors, are considered. The sideband weight uncertainty, the local oscillator, the pointing angle offsets and the measurement noise (NEDT), are considered as instrument uncertainties. Calibration errors consist of the hot target offset, the nonlinearity residual of the two-point calibration, use of the Rayleigh-Jeans (R-J) approximation and the choice of the antenna pattern. A priori profile errors of temperature, pressure and species are also considered. The results suggest that the antenna pattern mainly affects the retrievals in the troposphere. The NEDT is a major error source affecting all of the retrievals. The R-J approximation has a great impact upon the retrievals at $643 \mathrm{GHz}$, and should not be used. The local oscillator offset leads to an obvious error above $50 \mathrm{~km}$. The effect of nonlinearity residuals cannot be neglected above $70 \mathrm{~km}$. The impact of the sideband weight uncertainty and the hot target offset are relatively small. The pointing and the a priori errors can be neglected in most observation regions.
\end{abstract}

Keywords: TALIS; THz atmospheric limb sounding; error budget; retrievals

\section{Introduction}

Observation of the long-term evolution of the chemical species and the status of Earth's atmosphere is essential for scientists to understand the physical and chemical processes in the atmosphere and to assess the changes of climate. A satellite is the only platform which can provide the daily global coverage of this information. Generally, three ways of observation can be used to monitor atmosphere: nadir observation, occultation observation and limb observation. Limb sounding is more appropriate for atmospheric species detection, since it has good vertical resolution and wide altitude range [1]. Several frequency regions have been adopted to monitor the changes in the atmosphere, ranging from ultraviolet to terahertz. Among others, the terahertz frequency region has the advantage of being independent of the day-night cycle.

There are already many infrared limb sounders, such as MIPAS and SCIAMACHY on the Envisat satellite, and occultation instruments such as SAGE, SciSat-FTS and GOMOS used for middle and upper atmosphere detection.

Terahertz limb sounding techniques have been used for deriving the information of Earth's atmosphere for more than twenty years. The first Microwave Limb Sounder (MLS) onboard the Upper 
Atmosphere Research Satellite (UARS) launched in 1991 provided atmospheric data of temperature and species such as $\mathrm{ClO}, \mathrm{O}_{3}, \mathrm{H}_{2} \mathrm{O}, \mathrm{SO}_{2}, \mathrm{CH}_{3} \mathrm{CN}$ and $\mathrm{HNO}_{3}$ [2-4]. This information helps scientists understand the physical and chemical processes which lead to the $\mathrm{O}_{3}$ depletion. The Sub-Millimeter Radiometer (SMR) carried by the Odin satellite observed the atmospheric limb for half of the observation time, producing various species profiles in the middle atmosphere such as $\mathrm{O}_{3}, \mathrm{ClO}, \mathrm{N}_{2} \mathrm{O}, \mathrm{HNO}_{3}$, $\mathrm{H}_{2} \mathrm{O}, \mathrm{CO}$ and $\mathrm{NO}$, as well as isotopes of $\mathrm{H}_{2} \mathrm{O}, \mathrm{O}_{3}$ and ice clouds with a high vertical resolution of 1-2 km [5-8]. MLS onboard the Aura satellite has heritage from the UARS-MLS experiment, and it is improved to measure more species with better global and temporal coverage, better spatial resolution and better precision [9-13]. Its major productions include $\mathrm{OH}, \mathrm{HO}_{2}, \mathrm{H}_{2} \mathrm{O}, \mathrm{O}_{3}, \mathrm{HCl}, \mathrm{ClO}$, $\mathrm{HOCl}, \mathrm{BrO}, \mathrm{HNO}_{3}, \mathrm{~N}_{2} \mathrm{O}, \mathrm{CO}, \mathrm{HCN}, \mathrm{CH}_{3} \mathrm{CN}, \mathrm{SO}_{2}$ and the ice cloud [14]. The Superconducting Submillimeter-wave Limb-Emission Sounder (SMILES) onboard the Japanese Experiment Module (JEM) of the International Space Station (ISS) successfully demonstrated the performance of 4K-cooled Superconductor-Insulator-Superconductor (SIS) mixers, and gave observations of various chemical species [15-20].

Since Aura-MLS and Odin-SMR have worked for more than ten years, and the observation may be stopped in a few years, the follow-on instruments are imperatively needed to fill the gap. Currently, Stratospheric Inferred Winds (SIW) and SMILES-2 are being developed in Sweden and Japan, respectively [21-23]. SIW can measure horizontal wind vectors within $30-90 \mathrm{~km}$, and provide the profiles of temperature, $\mathrm{O}_{3}, \mathrm{H}_{2} \mathrm{O}$ and other species. SMILES-2 is designed to measure the horizontal wind vectors, temperature and molecules at the range of $15-180 \mathrm{~km}$.

The THz Atmospheric Limb Sounder (TALIS) is the first Chinese microwave limb sounder being developed in the National Space Science Center, the Chinese Academy of Sciences (NSSC, CAS). It is designed to measure atmospheric temperature, pressure and various chemical species, from 10 to $100 \mathrm{~km}$ with good precision and resolution. TALIS has four microwave radiometers covering 118, 190, 240 and $643 \mathrm{GHz}$. Fast Fourier Transform (FFT) spectrometers of $2 \mathrm{GHz}$ bandwidth with $2 \mathrm{MHz}$ resolution are used to improve the measurement performance. The observation performance of TALIS has been estimated in our previous study [24]. In this study, the impacts of the instrument uncertainties, calibration errors and a priori errors on the retrieval are estimated.

The instrument characteristics are described in Section 2. The sources of error and the simulation method of measurement are presented in Section 3. Then the results and analysis are given in Section 4. Finally, conclusions are provided in Section 5.

\section{Description of TALIS}

The THz Atmospheric Limb Sounder (TALIS) payload and observation characteristics are summarized in Table 1. The satellite for TALIS is designed at an orbit of $600 \mathrm{~km}$. TALIS will use four heterodyne microwave radiometers that operate at four frequency regions about $118 \mathrm{GHz}, 190 \mathrm{GHz}$, $240 \mathrm{GHz}$ and $643 \mathrm{GHz}$ to scan the atmospheric limb from about 0 to $100 \mathrm{~km}$. The $1.6 \mathrm{~m}$ offset parabolic antenna provides the field of view (FOV) at the tangent point of about $5.5 \mathrm{~km}, 3.8 \mathrm{~km}, 3.3 \mathrm{~km}$ and $0.96 \mathrm{~km}$, respectively. Two calibration targets (a hot target and an extra target) are set at the end of the arm. The hot target is used for the radiometer two-point calibration. The extra target is used to estimate the antenna effect and the nonlinearity. TALIS will view the hot target and the extra target at first for $3 \mathrm{~s}$, and then scan the limb from 0 to $100 \mathrm{~km}$ in $10 \mathrm{~s}$. Finally, it will view the cold space (used as a cold target) at $200 \mathrm{~km}$ for $5 \mathrm{~s}$. The process of retrace (from $200 \mathrm{~km}$ to the surface) is the same (also record data). Four heterodyne radiometers operate in double-sideband mode (DSB). Eleven FFT spectrometers of $2 \mathrm{GHz}$ bandwidth with $2 \mathrm{MHz}$ resolution will be used to improve the performance of the observation. The spectral bands of TALIS are summarized in Table 2. The $118 \mathrm{GHz}$ is used for temperature, $190 \mathrm{GHz}$ for $\mathrm{H}_{2} \mathrm{O}, 240 \mathrm{GHz}$ for $\mathrm{O}_{3}, 643 \mathrm{GHz}$ for $\mathrm{HCl}$ and other trade gases retrievals. More details are provided in [24]. 
Table 1. The main observation characteristics of the THz Atmospheric Limb Sounder (TALIS).

\begin{tabular}{cc}
\hline Characteristics & Value \\
\hline Satellite altitude & $600 \mathrm{~km}$ \\
Scan altitude & $0-100 \mathrm{~km}$ \\
Spectrum integration time & $0.1 \mathrm{~s}(1 \mathrm{~km})$ \\
Antenna vertical FOV & $5.5 \mathrm{~km}, 3.8 \mathrm{~km}, 3.3 \mathrm{~km}, 0.96 \mathrm{~km}$ \\
Spectrometer bandwidth & $2 \mathrm{GHz}$ \\
Spectrometer resolution & $2 \mathrm{MHz}$ \\
Local oscillator frequency & $117.55,190.1,239.66,642.87 \mathrm{GHz}$ \\
\hline
\end{tabular}

Table 2. The spectral bands of the TALIS.

\begin{tabular}{ccc}
\hline Radiometer (GHz) & Spectral Bands (GHz) & System Temperature (K) \\
\hline \multirow{2}{*}{118} & $115.35-117.35,117.75-119.75$ & $1000 \mathrm{~K}, \mathrm{DSB}$ \\
& $175.5-177.5,202.7-204.7 ;$ & \\
& $178.9-180.9,199.3-201.3 ;$ & $1000 \mathrm{~K}, \mathrm{DSB}$ \\
& $183.0-185.0,195.2-197.2$ & \\
& $229.66-231.66,247.66-249.66 ;$ & $1000 \mathrm{~K}, \mathrm{DSB}$ \\
& $232.16-234.16,245.16-247.16 ;$ & \\
& $234.66-236.66,242.66-244.66$ & $2300 \mathrm{~K}, \mathrm{DSB}$ \\
& $624.47-626.47,659.27-661.27 ;$ & \\
\hline
\end{tabular}

\section{Error Characterization and Simulation Method}

\subsection{Errors Description}

\subsubsection{Instrument Uncertainties}

Instrument uncertainties come from the instrument itself, and usually cannot be corrected completely. The impacts of instrument uncertainties which cannot be corrected have to be assessed in order to quantify the accuracy of such a retrieval [25].

In a radiometer, the heterodyne mixer will convert the signal which is coming from the antenna to the intermediate frequency. Double sideband (DSB) and single sideband (SSB) are two modes of receivers commonly used in the radiometer. The SSB mode can keep the complete spectral lines, while the DSB mode can cover more spectral lines, since the upper and lower sideband signals will be folded together. In addition, the system temperature of the DSB receiver is lower than that of the SSB receiver. However, a sideband weight inconsistency commonly exists in the double-sideband radiometer. The theoretical value of the output radiance of a DSB receiver can be described as [26]:

$$
I_{I F}^{i}\left(v_{I F}\right)=\frac{W_{S}(v) I_{A}^{i}(v)+W_{S}^{\prime}\left(v^{\prime}\right) I_{A}^{i}\left(v^{\prime}\right)}{W_{S}(v)+W_{S}^{\prime}\left(v^{\prime}\right)}
$$

where $i$ represents the channel, $v$ represents the measurement frequency, $v_{I F}$ is the intermediate frequency, $I_{I F}$ is the radiance after the mixer, $I_{A}$ is the radiance after the antenna, $W_{S}$ and $W_{S}^{\prime}$ are the lower and upper sideband response, respectively. In an ideal DSB radiometer, the sideband response of the lower and upper sideband should be consistent (0.5). In this simulation, an uncertainty of $0.2 \%$ is assumed in order to evaluate the retrieval error induced by the sideband weight. The assumed uncertainty of this sideband weight comes from our radiometer test.

The stability of local oscillator frequency is very important, since it controls which line will be detected. Although it is a systematic error that can be corrected before launch, the local oscillator frequency will vary over the time in which one year goes by. A $0.5 \mathrm{MHz}$ offset which may have 
occurred after several years is assumed to estimate the effect. This value of uncertainty is assumed according to the work by Baron et al. (2018) [21].

The geometrical tangent height is a key parameter, and is usually obtained from the satellite navigation system. However, the star tracker data is sometimes not very accurate, and the pointing angle (Line of sight, LOS) error should be considered. Fortunately, pointing can be retrieved along with temperature and species in a retrieval method. To estimate the effect, a $0.021^{\circ}(\sim 1 \mathrm{~km})$ offset is added to the simulation, and it will be retrieved simultaneously with the products. The uncertainty of the pointing offset is assumed according to the work of Baron et al. (2011) [17].

Measurement noise, that is noise equivalent differential temperature (NEDT) is the most important error that worsens the precision of retrievals. It is a statistical uncertainty that cannot be calibrated. The standard deviation (STD) can be calculated from the radiometric sensitivity equation:

$$
\epsilon=\frac{T_{\text {sys }}}{\sqrt{\beta d \tau}},
$$

where $T_{s y s}$ is the system noise temperature, which is the sum of the receiver temperature and the atmospheric temperature received by the antenna, $\beta$ is the noise equivalent spectral resolution, and $d \tau$ is the integration time for measuring a single spectrum.

The assumed instrument uncertainties are summarized in Table 3.

Table 3. Uncertainties assumed for instrument.

\begin{tabular}{cc}
\hline Source & Value \\
\hline Sideband weight & $0.2 \%$ \\
Local oscillator & $0.5 \mathrm{MHz}$ \\
Pointing offset (LOS) & $0.021^{\circ}$ \\
Measurement noise (NEDT) & $2.2 \mathrm{~K}, 2.2 \mathrm{~K}, 2.2 \mathrm{~K}, 5.1 \mathrm{~K}$ \\
\hline
\end{tabular}

\subsubsection{Calibration Errors}

Calibration is important, since it can produce the calibrated limb radiances. These errors in calibration should be avoided in some degree. However, residual errors will also remain after data processing.

The two-point calibration is a widely used method for microwave radiometer calibration $[27,28]$. The schematic of two-point calibration is illustrated in Figure 1.

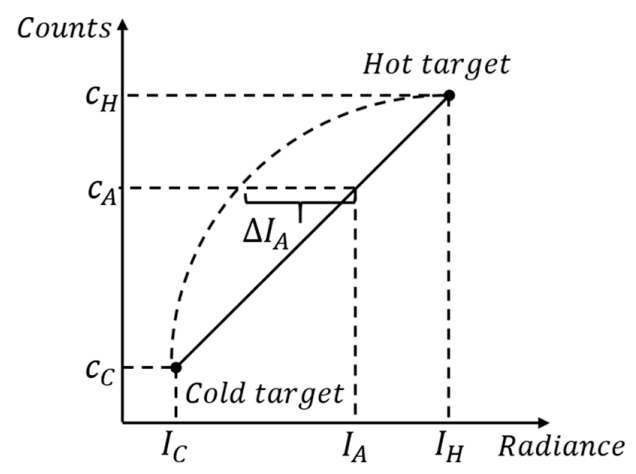

Figure 1. Schematic of two-point calibration.

The two-point calibration equation can be established as [29]:

$$
I_{A}^{i}=\frac{C_{A}^{i}-C_{C}^{i}}{C_{H}^{i}-C_{C}^{i}}\left(I_{H}^{i}-I_{C}^{i}\right)+I_{C}^{i}+\Delta I_{A}^{i},
$$




$$
\Delta I_{A}^{i}=u\left(I_{H}^{i}-I_{C}^{i}\right)^{2} \frac{\left(C_{A}^{i}-C_{H}^{i}\right)\left(C_{A}^{i}-C_{C}^{i}\right)}{\left(C_{H}^{i}-C_{C}^{i}\right)^{2}},
$$

where $i$ represents the channel, $C_{A}, C_{H}, C_{C}$ are the counts of Earth, hot and cold targets, respectively. $I_{H^{\prime}} I_{C}$ are the radiance of the hot target and the cold space obtained by the instrument, respectively. $\Delta I_{A}$ means the system nonlinearity difference, $u$ is the nonlinearity coefficient. The possible error sources from calibration are the residual nonlinearity radiance of calibration and the hot target offset, due to the instability of the calibration target. In this study, the hot target temperature is added by a $-0.5 \mathrm{~K}$ offset to produce the uncertainty in calibration. The residual nonlinearity brightness temperature is set to a standard deviation of $0.3 \mathrm{~K}$, which is a typical value measured by the radiometer test. Another possible source of error is the Rayleigh-Jeans (R-J) approximation used in radiometric calibration [30]. R-J approximation can convert radiance to brightness temperature by using a linear equation, and is widely used in radiometric calibration at the MMW band up to the $\mathrm{THz}$ band. However, R-J approximation will lead to a brightness temperature error which varies with frequency and temperature, and it is not easily corrected by adding an offset. In this simulation, $I$ in Equation (3) is replaced by $T$ when using the R-J approximation, and $T_{C}$ and $T_{H}$ are set to $2.73 \mathrm{~K}$ and $300 \mathrm{~K}$, respectively. The variations of calibration errors with temperature and count ratio are shown in Figure 2. The count ratio means $\frac{C_{A}-C_{C}}{C_{H}-C_{C}}$. Figure 2 shows that although the differences $T_{R J}-T_{B}$ seem to be a constant error above $50 \mathrm{~K}$, it also varies with count ratio. So, it cannot be corrected easily.
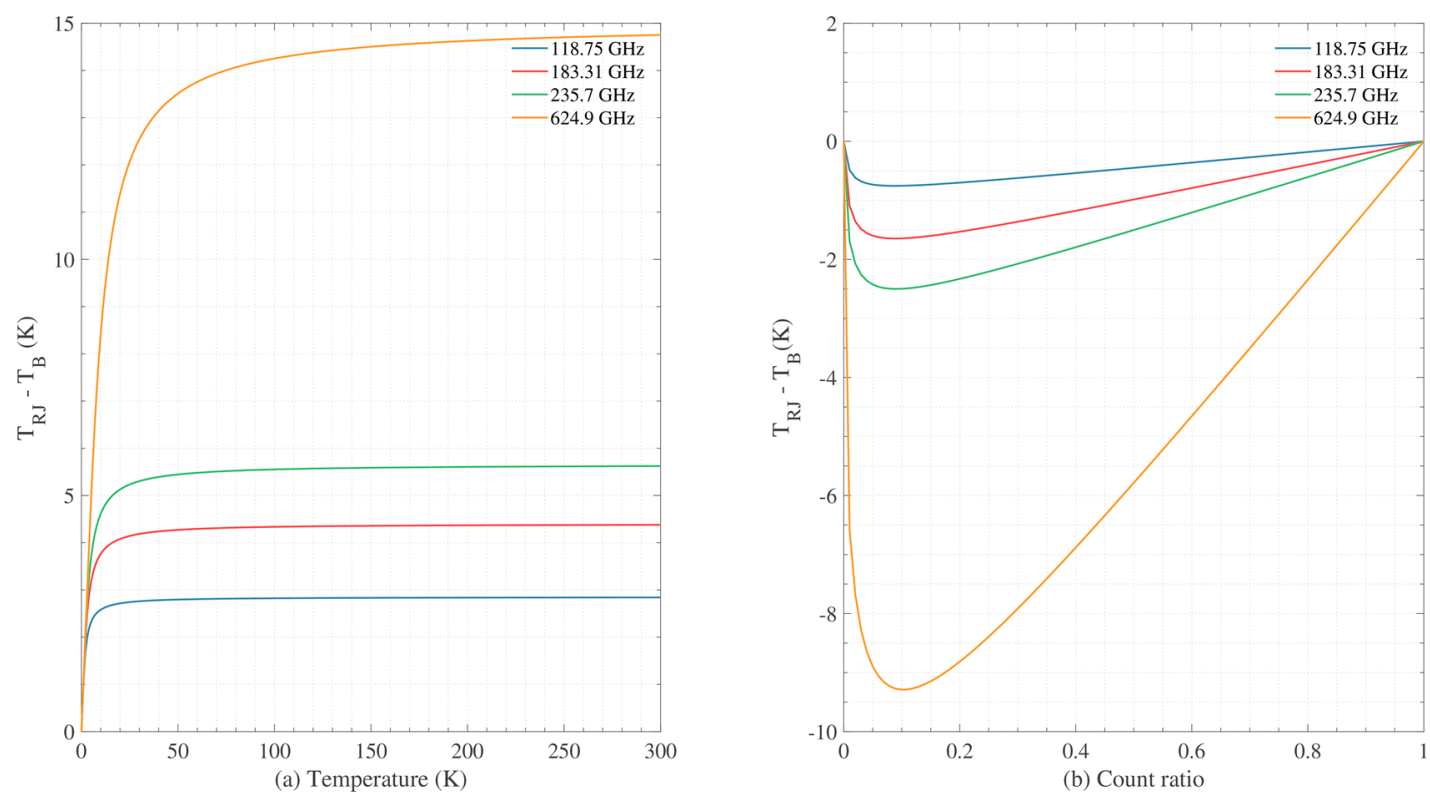

Figure 2. The variations of calibration errors with temperature and the count ratio induced by the R-J approximation: (a) variations with temperature; (b) variations with the count ratio. Here $T_{B}$ is calculated by Equation (3), and $T_{R J}$ is obtained from replacing $I$ by $T$ with $T_{C}$ and $T_{H}$ set to 2.73 and $300 \mathrm{~K}$, respectively. The count ratio means $\frac{C_{A}-C_{C}}{C_{H}-C_{C}}$.

TALIS measures atmospheric limb radiances captured by the antenna. The radiance which is accepted by the antenna can be expressed by:

$$
I_{A}^{i}=\int_{\text {band }} F(v) \int_{\Omega} I_{B}^{i}(\Omega) W_{A}(\Omega) d \Omega d v,
$$

where $i$ represents the channel, $I_{A}^{i}$ represents the antenna received radiance, $I_{B}^{i}$ represents the radiance emitted from the atmosphere, $W_{A}$ describes the normalized antenna response function, $F(v)$ describes 
the frequency response of the radiometer, and $\Omega$ is the solid angle. The integrals are estimated over the full range of frequencies and solid angles where instrument response exists.

Using the Planck function to convert the radiance to brightness temperature, the antenna temperature can be described [31-33]:

$$
\begin{gathered}
T_{A}^{\prime}=\eta T_{A}+(1-\eta) T_{s p} \\
T_{A}=\eta_{a} T_{B}+\left(1-\eta_{a}\right) T_{S},
\end{gathered}
$$

where $T_{A}^{\prime}$ represents the antenna temperature, $T_{A}$ represents the earth scene component of the antenna temperature, $T_{S P}$ represents the spillover emission, $\eta$ represents the coefficient of spillover correction. In addition, $T_{B}$ is the atmospheric emission brightness temperature, $\eta_{a}$ is the main beam efficiency and $T_{S}$ is the sidelobe contribution.

Antenna pattern plays an important role in atmospheric limb sounding, since the atmospheric profiles varies rapidly in some regions. The antenna patterns of TALIS are shown in Figure 3, and the fields of view (FOVs) are $5.5 \mathrm{~km}, 3.8 \mathrm{~km}, 3.3 \mathrm{~km}$ and $0.96 \mathrm{~km}$, respectively. Usually, a $3 \mathrm{~dB}$ beamwidth (full width between half-power points) of the antenna pattern is considered as the main beam. However, the sidelobe contribution is not easily estimated, and this has a large impact on the measured radiance, especially in the limb sounding. Thus, how the antenna pattern affects the retrievals should be evaluated. In this simulation study, 2.5 times the main beamwidth of the antenna patterns is used to calculate the measured radiances, since it is usually used to represent the whole antenna pattern in calculation. The antenna patterns of the main beamwidth are used in retrieval in order to estimate the retrieval errors that may be induced by the antenna.

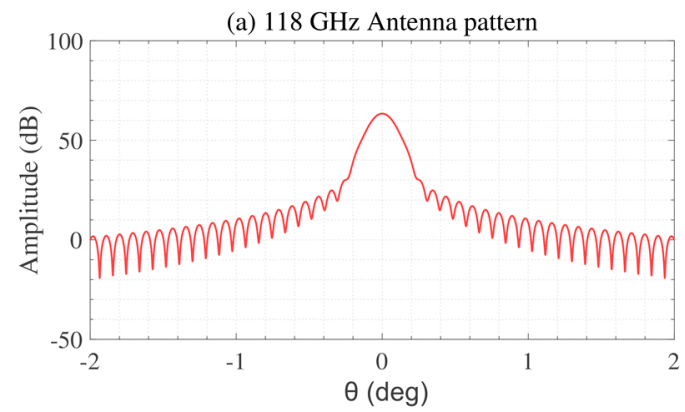

(c) $240 \mathrm{GHz}$ Antenna pattern

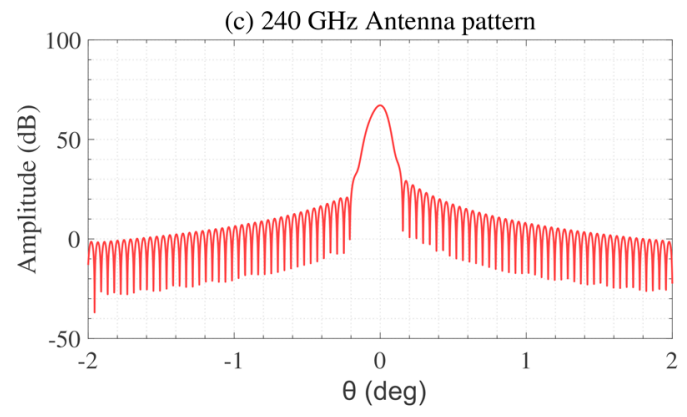

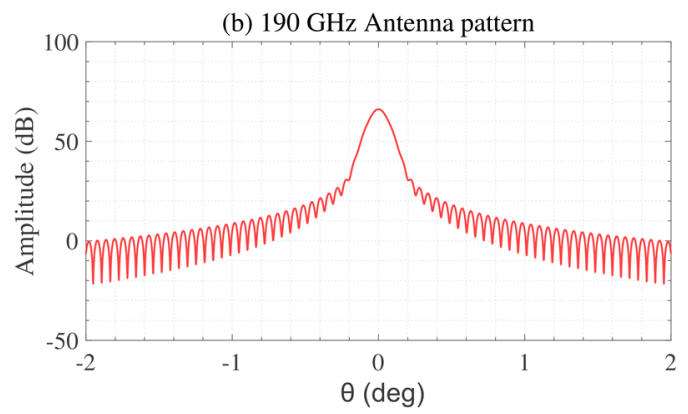

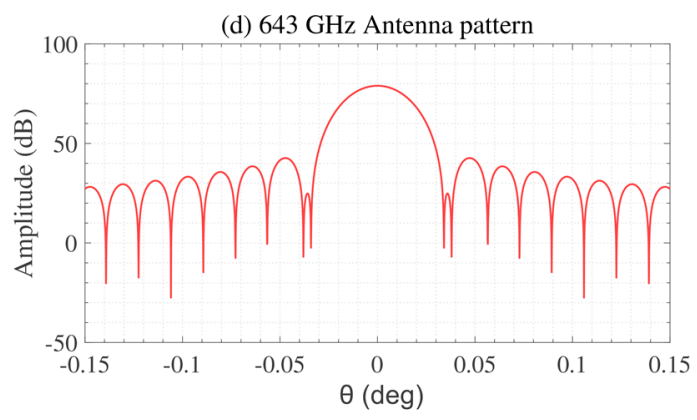

Figure 3. The antenna pattern of TALIS: (a) the $118 \mathrm{GHz}$ antenna pattern; (b) the $190 \mathrm{GHz}$ antenna pattern; (c) the $240 \mathrm{GHz}$ antenna pattern; (d) the $643 \mathrm{GHz}$ antenna pattern.

The assumed errors are summarized in Table 4. 
Table 4. Errors assumed for calibration.

\begin{tabular}{cc}
\hline Source & Value \\
\hline Hot target offset & $-0.5 \mathrm{~K}$ \\
Nonlinearity & $0.3 \mathrm{~K}$ \\
R-J approximation & $/$ \\
Antenna pattern used & $3 \mathrm{~dB}$ FWHM \\
\hline
\end{tabular}

\subsubsection{A Priori Errors}

The external errors mainly come from the forward model and the a priori profiles of temperature, species and pressure. The model error could not be estimated, since there is no absolute value that can be measured. So, no forward model errors are applied in this study.

The trace gas species can be retrieved by using the optimal estimation (OEM) retrieval method, which requires good knowledge of the atmospheric profiles as well as the measurement noise [34]. Since the method involves the nonlinear weighted least squares optimization and includes the use of a priori constraints for regularization, the a priori data mainly affects the region where measurement information is lacking, and the noise dominates the region where the measurement signal is large [35].

To estimate the effect of the a priori profile, the species profiles are multiplied by $120 \%$, which is to serve as the a priori profiles, and the temperature profile is added as a $5 \mathrm{~K}$ offset. They are the standard deviation commonly used in building the a priori covariance matrix [36]. Pressure can be retrieved together with temperature, and a $5 \%$ error is added to the pressure profile to be the a priori pressure profile.

The assumed uncertainties are summarized in Table 5.

Table 5. Uncertainties assumed for external errors.

\begin{tabular}{cc}
\hline Source & Value \\
\hline Temperature a priori & $5 \mathrm{~K}$ \\
Pressure a priori & $5 \%$ \\
Species a priori & $20 \%$ \\
\hline
\end{tabular}

\subsection{Model and Retrieval Method}

In order to retrieve the atmospheric information, an accurate forward model which can simulate the radiative transfer, spectroscopy and instrumental characteristics, are necessary. In limb sounding, scattering can usually be neglected above the upper troposphere, since there are almost no clouds at these altitudes. While polar stratospheric clouds can be present, the particle sizes are smaller than the TALIS observation wavelengths.

The cloud-free radiative transfer equation can be described as:

$$
I_{B}\left(S_{2}\right)=I_{B}\left(S_{1}\right) e^{-\tau\left(S_{1}, S_{2}\right)}+\int_{S_{1}}^{S_{2}} \alpha(s) B(T) e^{-\tau\left(S, S_{2}\right)} d s,
$$

where $I_{B}$ is the radiance, $\alpha$ is the absorption coefficient, $S_{1}$ and $S_{2}$ means the two position of the radiance, and $\tau$ is the opacity or optical thickness. $B(T)$ represents the atmospheric emission which is given by the Planck function.

The optimal estimation method (OEM) is the most widely used retrieval method in atmospheric sounding [34]. The cost function in the retrieval method can be defined as:

$$
\chi^{2}=[\boldsymbol{y}-\boldsymbol{F}(\boldsymbol{x}, \boldsymbol{b})]^{T} \boldsymbol{S}_{y}^{-1}[\boldsymbol{y}-\boldsymbol{F}(\boldsymbol{x}, \boldsymbol{b})]+\left[\boldsymbol{x}-\boldsymbol{x}_{a}\right]^{T} \boldsymbol{S}_{a}^{-1}\left[\boldsymbol{x}-\boldsymbol{x}_{a}\right],
$$

where $x_{a}$ is a priori state vector, $S_{a}$ and $S_{y}$ are the covariance matrices representing the variability of the state vector and the measurement error vector, respectively. The core theory of OEM is to compare 
the simulated radiance $F(x, b)$ with the observed radiance $y$ until the state which minimizes the $\chi^{2}$ could be found.

The Levenberg-Marquardt method, which is the modification of the Gauss-Newton iterative, is used to solve the nonlinear problem [37]. The solution is given by:

$$
\boldsymbol{x}_{i+1}=\boldsymbol{x}_{i}+\left[(\boldsymbol{I}+\gamma) \boldsymbol{S}_{a}^{-1}+\boldsymbol{K}_{x i}{ }^{T} \boldsymbol{S}_{y}^{-1} \boldsymbol{K}_{i}\right]^{-1}\left\{\boldsymbol{K}_{x i}{ }^{T} \boldsymbol{S}_{y}^{-1}\left[\boldsymbol{y}-\boldsymbol{F}\left(\boldsymbol{x}_{i}\right)\right]-\boldsymbol{S}_{a}^{-1}\left(\boldsymbol{x}_{i}-\boldsymbol{x}_{a}\right)\right\},
$$

where $\gamma$ denotes the Levenberg-Marquardt parameter, and $\boldsymbol{K}_{x i}$ represents the weighting function matrix (Jacobian).

The error estimates induced by random and systematic uncertainties are given by:

$$
\varepsilon=\left|\hat{x}-\hat{x}_{0}\right|,
$$

where $\varepsilon$ is the error induced by perturbing the parameters and $\hat{x}$ is the state vector retrieved after changing the parameter according to its uncertainty, while $\hat{x}_{0}$ is the state vector retrieved before changing the parameter.

In the following simulations, the Atmospheric Radiative Transfer Simulator (ARTS) is used to calculate the measured radiance [38]. The retrieval tool is Qpack, which is the OEM tool developed for interaction with ARTS [39]. Temperature, $\mathrm{H}_{2} \mathrm{O}, \mathrm{O}_{3}$ and $\mathrm{HCl}$ are treated as main products of the $118 \mathrm{GHz}, 190 \mathrm{GHz}, 240 \mathrm{GHz}$ and $643 \mathrm{GHz}$ radiometers, respectively. A mid-latitude summer atmospheric condition extracted from FASCOD, which is provided by ARTS, is chosen to perform the simulation, and local spherical homogeneity is assumed. A vertical retrieval grid of $2.5 \mathrm{~km}$ resolution is selected. The choice of a retrieval grid is closely related to the antenna field of view (FOV). Generally speaking, the resolution of the retrieval grid should match the antenna FOV. Degrading the vertical resolution can improve the retrieval precision and increase the retrieval speed. The retrieval precision of the four radiometers with different retrieval grids are shown in Figure 4. There is usually a trade-off between precision and resolution according to different applications.
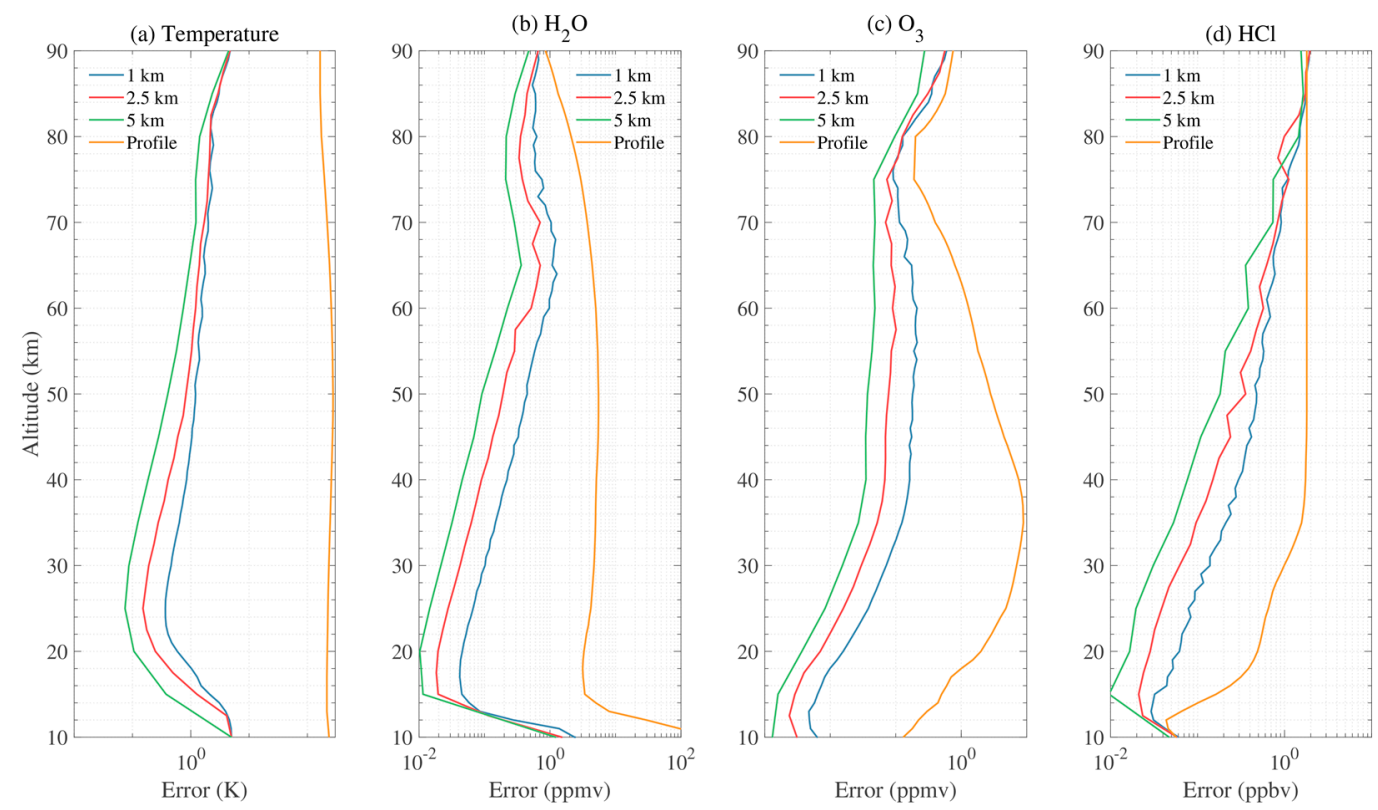

Figure 4. The retrieval precision of the four radiometers with different retrieval grids, and only random noises are added: (a) $118 \mathrm{GHz}$ temperature retrieval; (b) $190 \mathrm{GHz} \mathrm{H} 2 \mathrm{O}$ retrieval; (c) $240 \mathrm{GHz} \mathrm{O} 3$ retrieval; (d) $643 \mathrm{GHz} \mathrm{HCl} \mathrm{retrieval.} \mathrm{The} 1 \mathrm{~km}, 2.5 \mathrm{~km}, 5 \mathrm{~km}$ represent the different retrieval grids. The "Profile" represents the typical profile. 


\section{Results}

\section{1. $118 \mathrm{GHz}$}

The temperature retrieval errors induced by instrument uncertainties are shown in Figure 5. The error induced by local oscillator offset (LO) is around $5 \mathrm{~K}$ above $60 \mathrm{~km}$, since the line width is quite narrow in the upper atmosphere. Sideband weight causes an error of $1 \mathrm{~K}$ in the stratosphere. This is because of the large brightness temperature difference between the lower sideband (18 K at $30 \mathrm{~km})$ and the upper sideband $(250 \mathrm{~K}$ at $30 \mathrm{~km})$. NEDT is the mainly considered error in normal retrieval which cannot be alleviated through calibration. It leads to an error of less than $2 \mathrm{~K}$. The effect of pointing error (LOS) is less than $0.5 \mathrm{~K}$ above $15 \mathrm{~km}$, because it can be retrieved simultaneously with temperature.
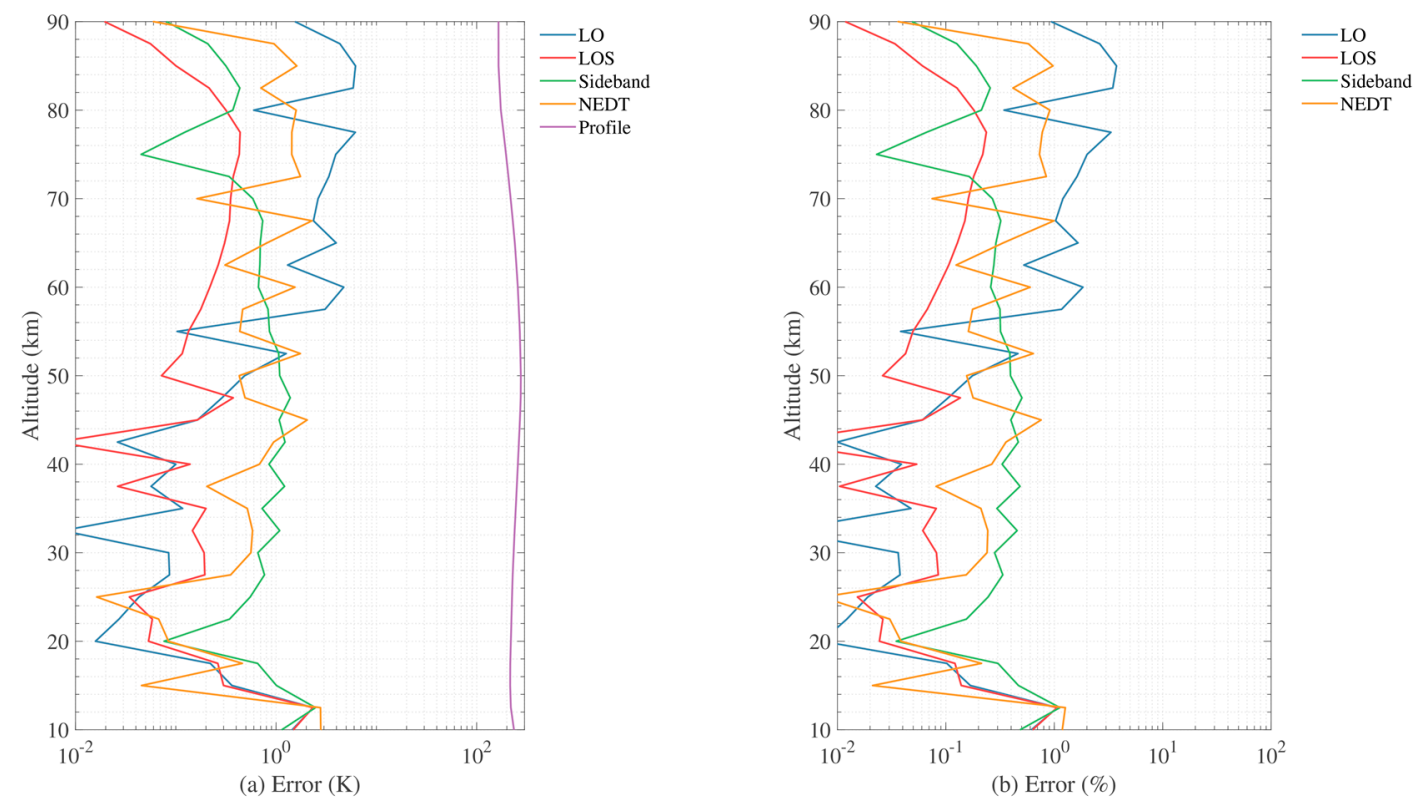

Figure 5. The temperature retrieval errors induced by different instrument uncertainty sources: (a) absolute and (b) relative retrieval errors. The uncertainties assumed are summarized in Table 3.

The antenna pattern plays an important role in the $118 \mathrm{GHz}$ observation. The brightness temperature difference $T_{A}-T_{B}$ at various tangent heights is shown in Figure 6. The impact of the $118 \mathrm{GHz}$ antenna pattern on the measurement can be as large as $15 \mathrm{~K}$ at the tangent height of $20 \mathrm{~km}$ in the spectral line wings, since the temperature profile varies rapidly in this region. Although the difference will decrease with the tangent height increasing, the offset is still larger than $2.5 \mathrm{~K}$ at $90 \mathrm{~km}$. This is due to the large FOV $(5.5 \mathrm{~km})$ of the $118 \mathrm{GHz}$ antenna. The impact of the antenna pattern width error on the retrieval errors is presented below.

Figure 7 shows the temperature retrieval errors induced by different calibration uncertainties. The temperature retrieval error induced by the antenna pattern can be as large as $20 \mathrm{~K}$ below $25 \mathrm{~km}$ and less than $1 \mathrm{~K}$ in the middle atmosphere. The error due to the $\mathrm{R}-\mathrm{J}$ approximation is about $1-2 \mathrm{~K}$ in this frequency band. The hot target offset causes an error of $0.7 \mathrm{~K}$ above $15 \mathrm{~km}$.

The most nonlinear effects of calibration can be corrected in the processing of the radiometer calibration by using Equation (4). Although there exists a residual of about $0.3 \mathrm{~K}$ (STD), its impact on temperature retrieval is relatively small.

The temperature retrieval errors induced by the a priori errors are shown in Figure 8. The effect of pressure uncertainty is less than $0.5 \mathrm{~K}$, since it can be retrieved with temperature simultaneously through the hydrostatic equilibrium equation. The a priori profile mainly affects the region where the measurement information lacked, such as the troposphere and upper mesosphere. The error is larger than $1 \mathrm{~K}$ above $85 \mathrm{~km}$. 

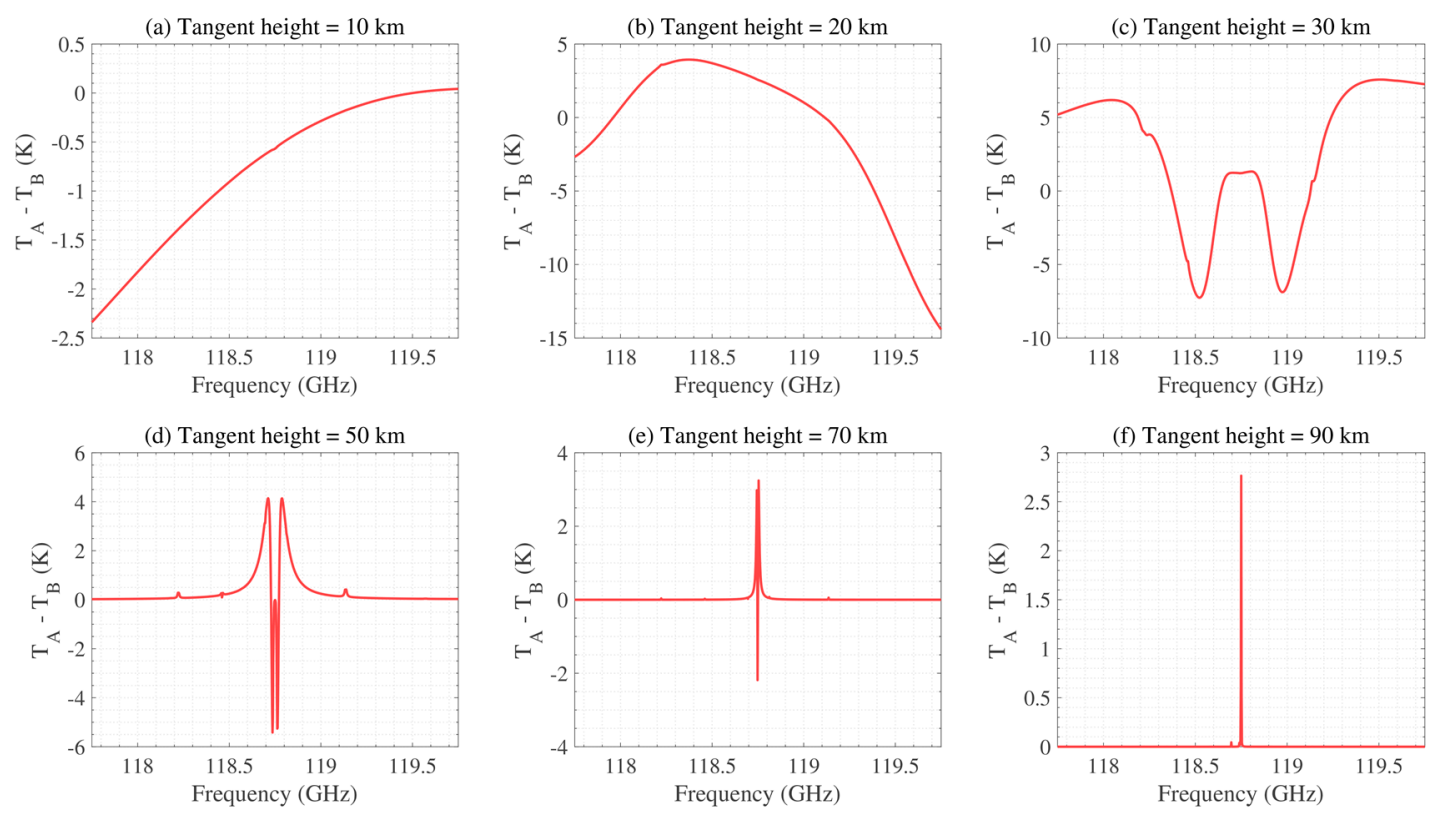

Figure 6. The brightness temperature difference $T_{A}-T_{B}$ at various tangent height measured by the $118 \mathrm{GHz}$ radiometer: (a) $10 \mathrm{~km}$; (b) $20 \mathrm{~km}$; (c) $30 \mathrm{~km}$; (d) $50 \mathrm{~km}$; (e) $70 \mathrm{~km}$; (f) $90 \mathrm{~km}$.
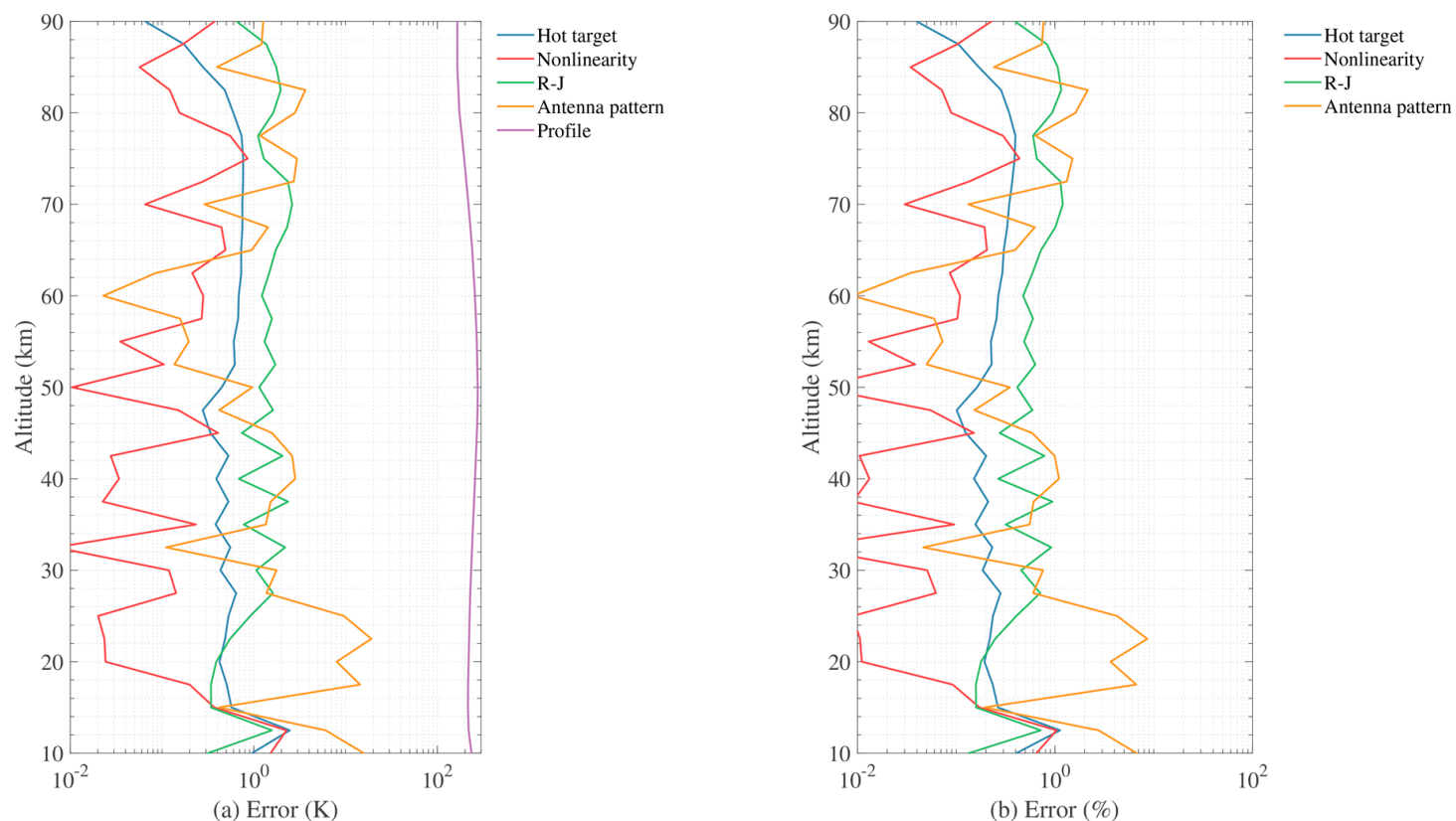

(b) Error $(\%)$

Figure 7. The temperature retrieval errors induced by different calibration error sources: (a) absolute and (b) relative retrieval errors. The uncertainties assumed are summarized in Table 4.

\section{2. $190 \mathrm{GHz}$}

The $\mathrm{H}_{2} \mathrm{O}$ retrieval errors induced by various instrument uncertainties are shown in Figure 9. NEDT is the major error source which leads to about $10 \%-40 \%$ relative error above $60 \mathrm{~km}$ and less than $3 \%$ below. The effect of local oscillator offset (LO) is as large as $10 \%$ at $65-75 \mathrm{~km}$ and can be neglected below $50 \mathrm{~km}$. Sideband weight also has an impact of $1 \%$ in this frequency band. The error due to pointing offset (LOS) can be neglected since it can be retrieved accurately. 

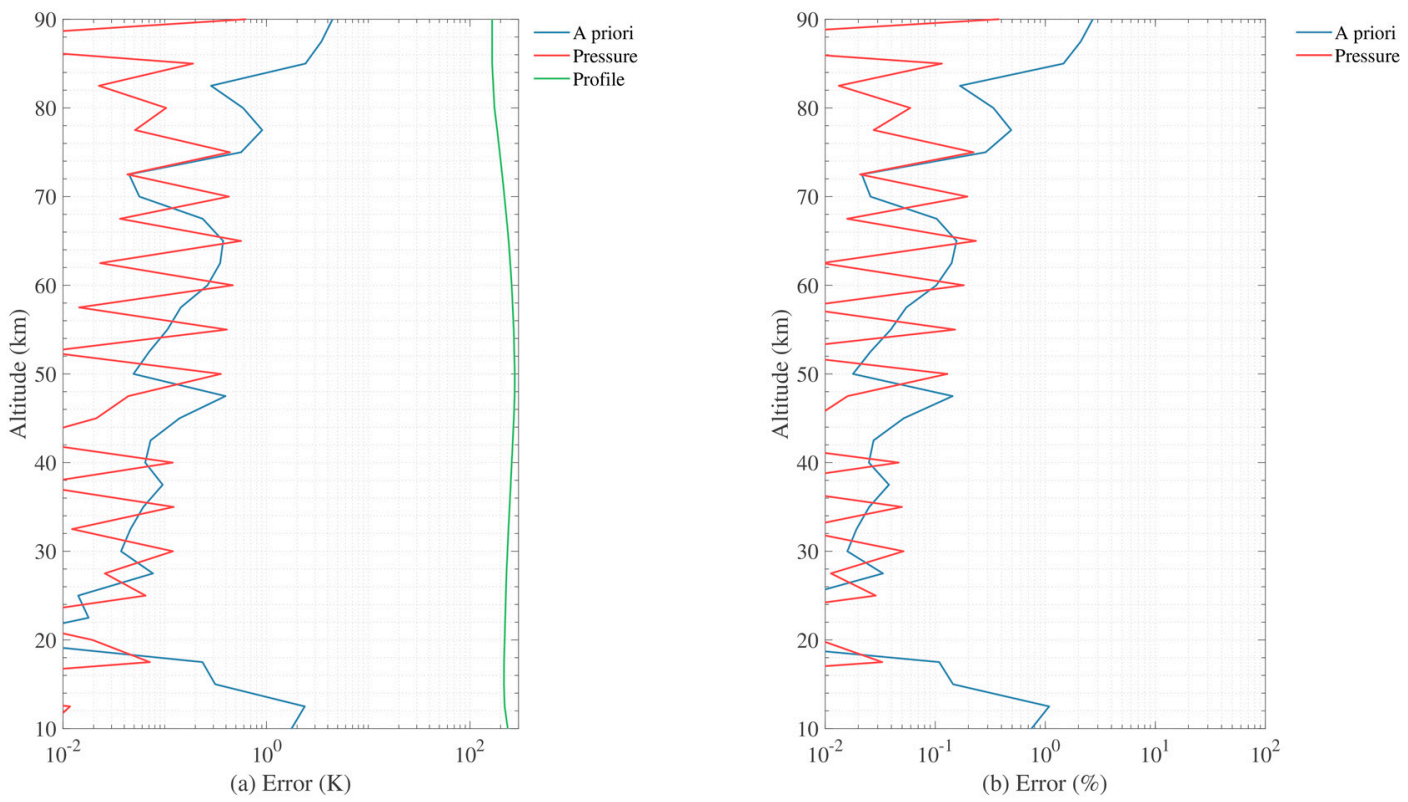

Figure 8. The temperature retrieval errors induced by external error sources: (a) absolute and (b) relative retrieval errors. The uncertainties assumed are summarized in Table 5.

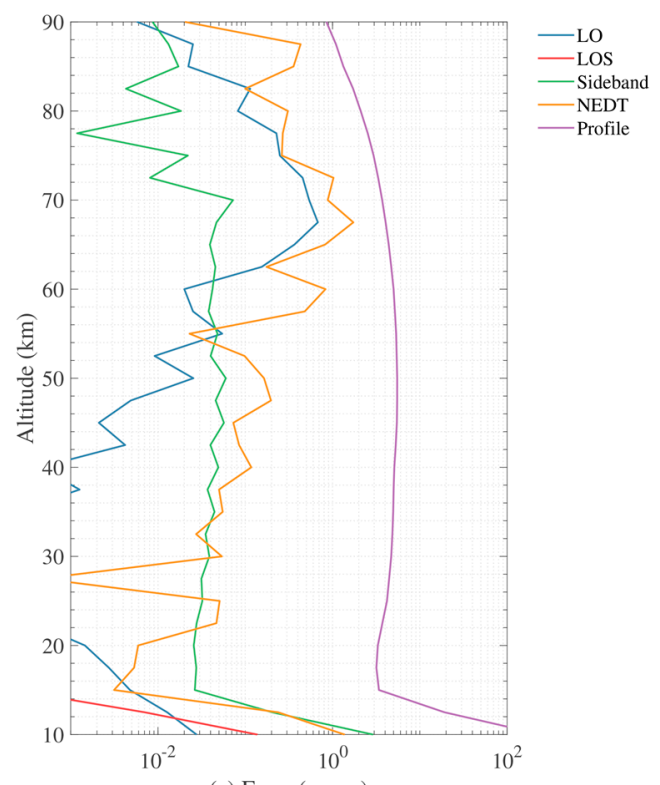

(a) Error (ppmv)

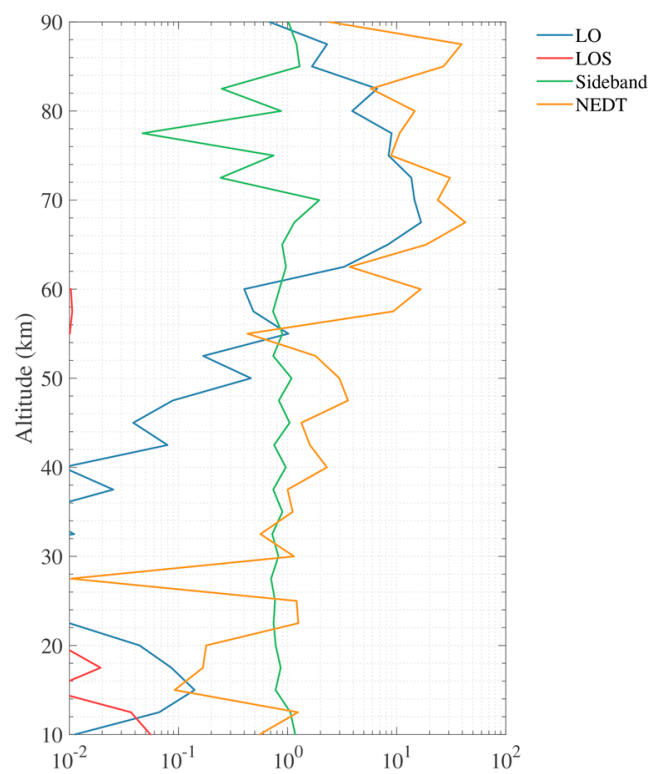

(b) Error $(\%)$

Figure 9. The $\mathrm{H}_{2} \mathrm{O}$ retrieval errors induced by different instrument uncertainty sources: (a) absolute and (b) relative retrieval errors. The uncertainties assumed are summarized in Table 3.

The brightness temperature difference $T_{A}-T_{B}$ at various tangent heights measured by $190 \mathrm{GHz}$ radiometer (183 GHz spectrometer) are shown in Figure 10. The impact of the antenna pattern mainly exists at the tangent height of $10 \mathrm{~km}$ where the $\mathrm{VMR}$ of $\mathrm{H}_{2} \mathrm{O}$ is large and changing rapidly. The largest brightness temperature can be $11 \mathrm{~K}$. The impact is decreasing with the tangent height increasing. The antenna effect is small compared with that of $118 \mathrm{GHz}$ radiometer.

Figure 11 shows the $\mathrm{H}_{2} \mathrm{O}$ retrieval errors induced by different calibration uncertainties. R-J approximation is the main error source which will lead to a retrieval error of $7 \%$ below $60 \mathrm{~km}$. The retrieval error induced by antenna pattern can be as large as $50 \%$ at $15 \mathrm{~km}$ since the VMR of $\mathrm{H}_{2} \mathrm{O}$ changes rapidly in this region. At the altitude above $20 \mathrm{~km}$, the antenna pattern has a less impact on the 
retrieval $(<5 \%)$. The hot target offset only causes an error of less than $0.5 \%$ above $20 \mathrm{~km}$. The residual nonlinearity of calibration causes an error of less than $1 \%$ below $65 \mathrm{~km}$ and leads to a $4 \%$ error above.
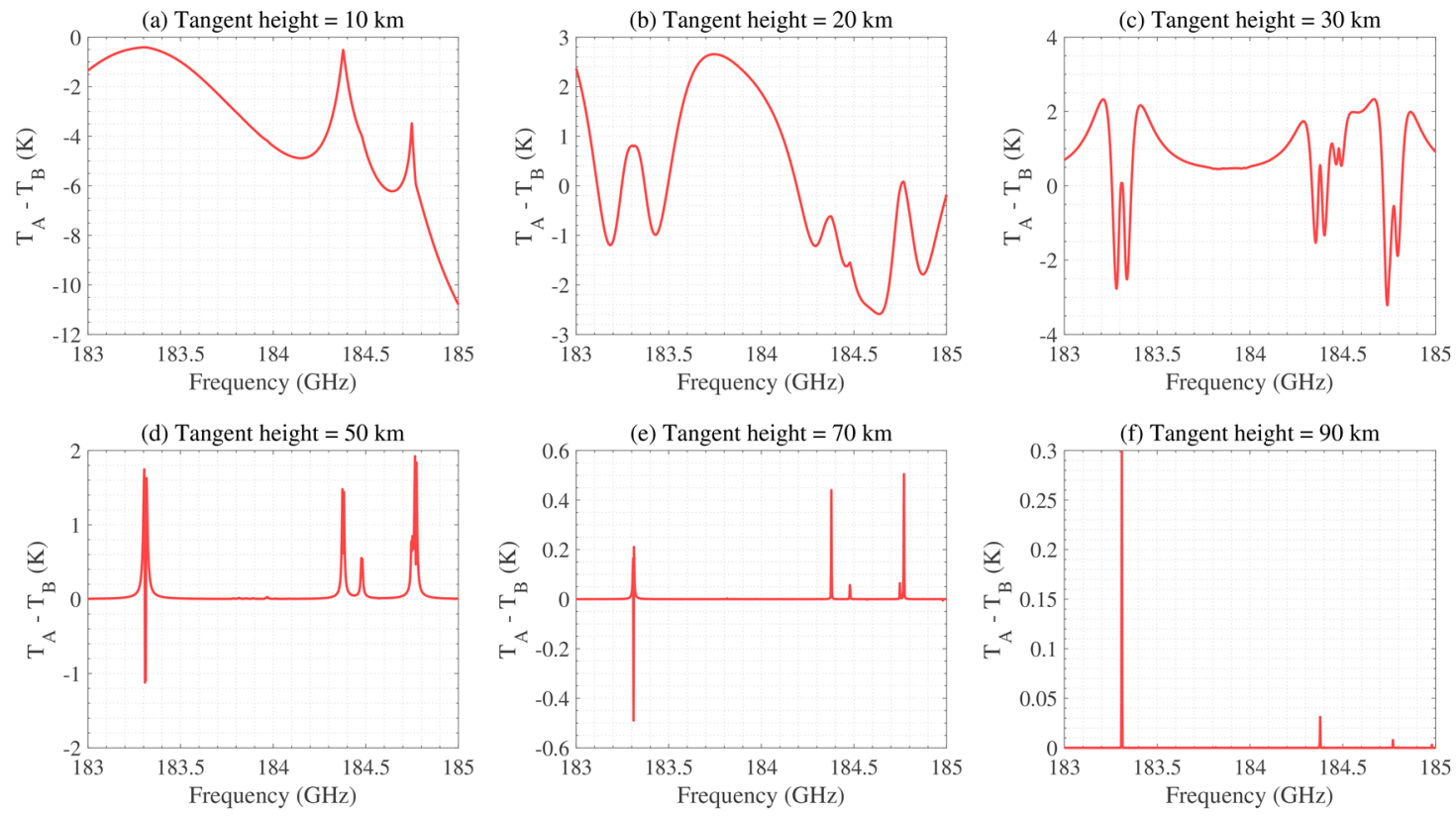

Figure 10. The brightness temperature difference $T_{A}-T_{B}$ at various tangent height measured by $190 \mathrm{GHz}$ radiometer (183 GHz spectrometer): (a) $10 \mathrm{~km}$; (b) $20 \mathrm{~km}$; (c) $30 \mathrm{~km}$; (d) $50 \mathrm{~km}$; (e) $70 \mathrm{~km}$; (f) $90 \mathrm{~km}$.
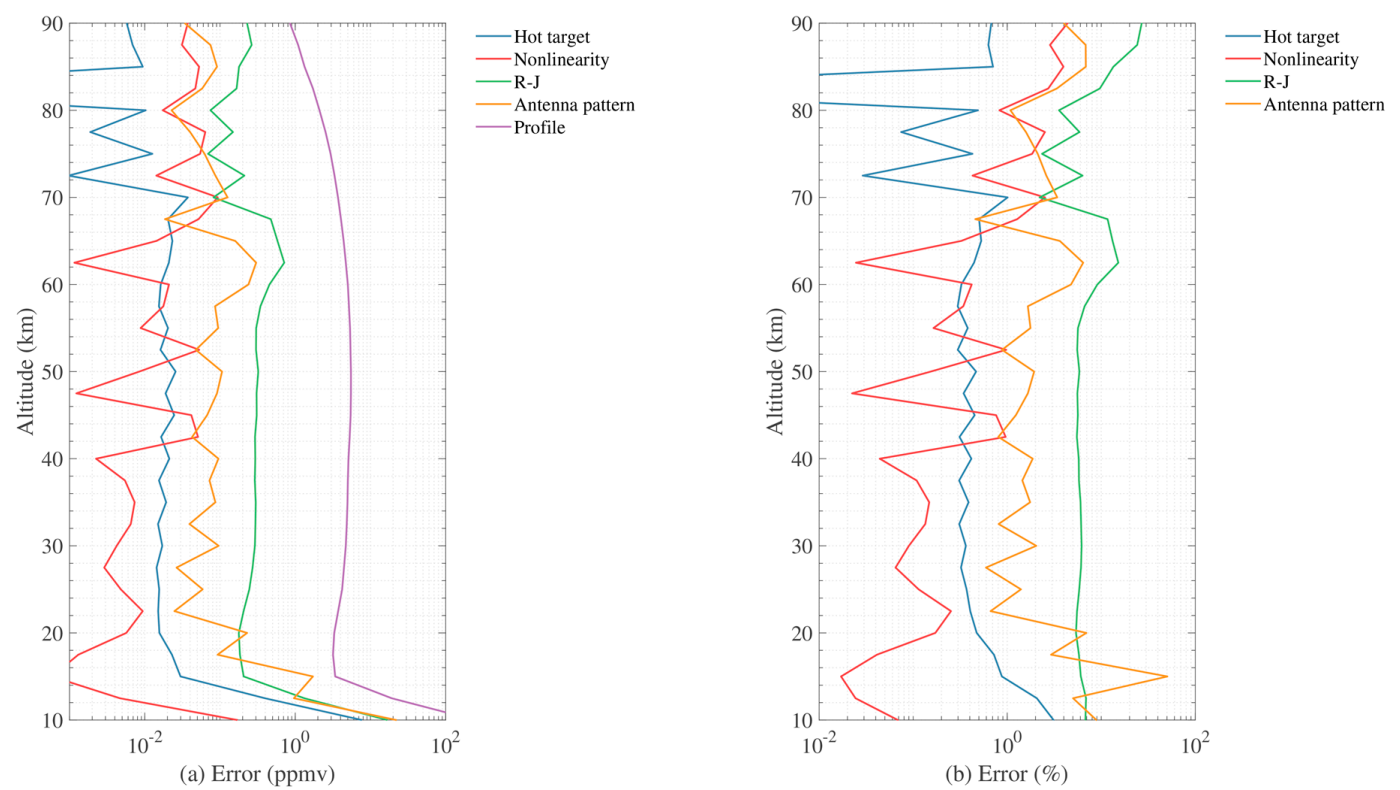

Figure 11. The $\mathrm{H}_{2} \mathrm{O}$ retrieval errors induced by different calibration error sources: (a) absolute and (b) relative retrieval errors. The uncertainties assumed are summarized in Table 4 .

The $\mathrm{H}_{2} \mathrm{O}$ retrieval errors induced by a priori errors are shown in Figure 12. The retrieval errors induced by the error of the a priori profile can be neglected below $80 \mathrm{~km}$. The errors above come from the a priori profile itself, since there is no information observed in this region. 

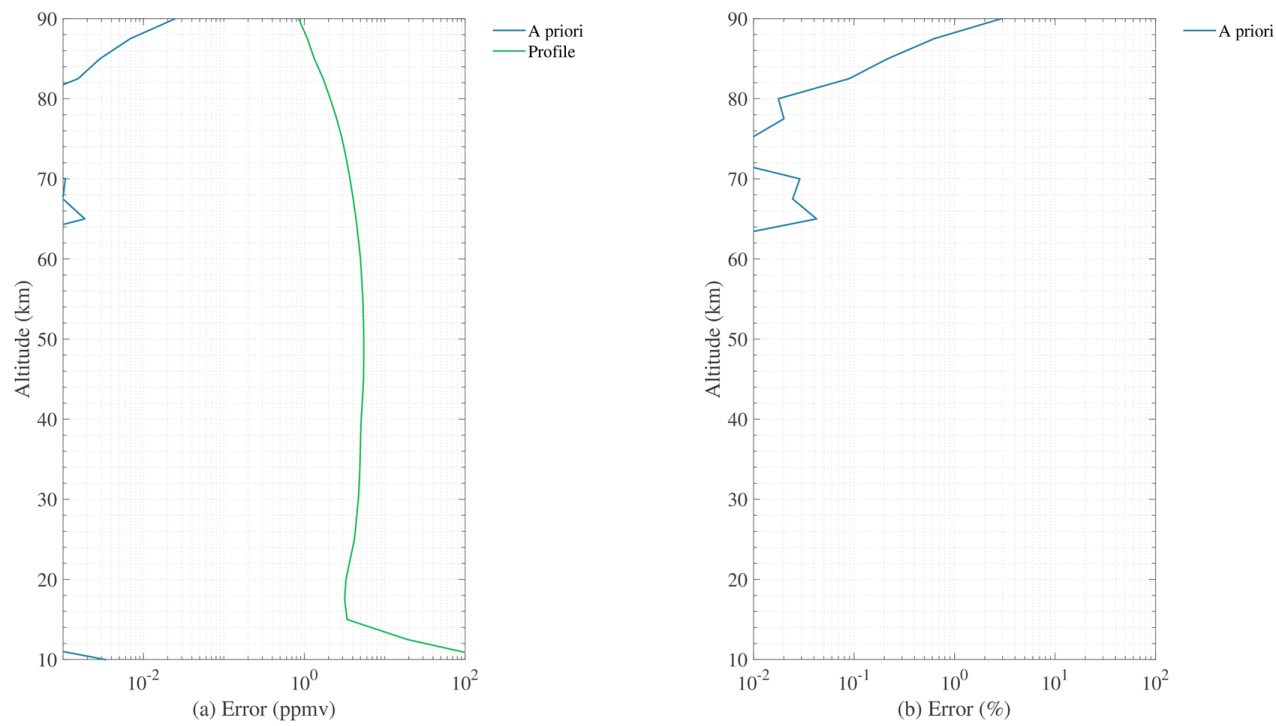

Figure 12. The $\mathrm{H}_{2} \mathrm{O}$ retrieval error induced by external error source: (a) absolute and (b) relative retrieval errors. The uncertainties assumed are summarized in Table 5.

\section{3. $240 \mathrm{GHz}$}

The $\mathrm{O}_{3}$ retrieval errors induced by various instrument uncertainties are shown in Figure 13. NEDT is the major error source in the middle and upper atmosphere which leads to an error of $10 \%-50 \%$ above $60 \mathrm{~km}$. The local oscillator offset (LO) plays a secondary important role in instrument uncertainties above $60 \mathrm{~km}$ with an error of around 10\%. The impact below can be neglected, since the line width is quite large compared with $0.5 \mathrm{MHz}$. The effect of sideband weight and pointing offset (LOS) has almost no influence in the observation region.
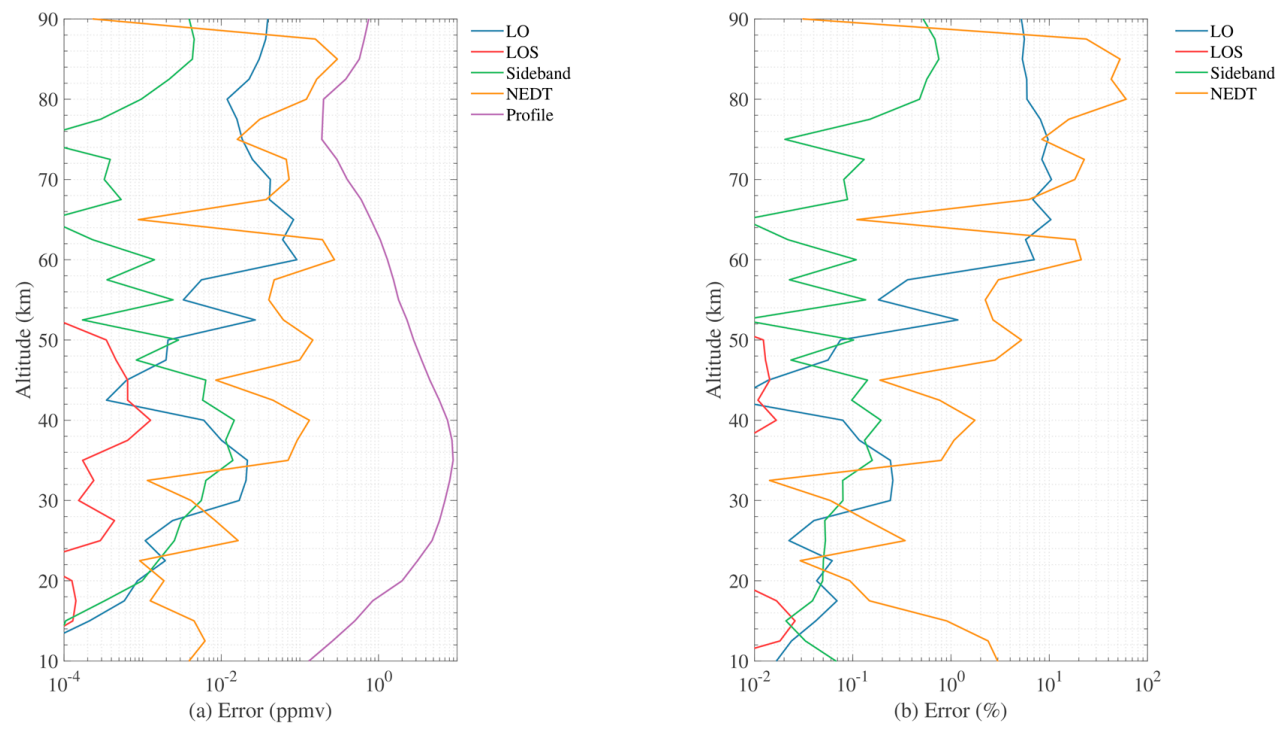

Figure 13. The $\mathrm{O}_{3}$ retrieval errors induced by different instrument uncertainty sources: (a) absolute and (b) relative retrieval errors. The uncertainties assumed are summarized in Table 3.

The brightness temperature difference $T_{A}-T_{B}$ at various tangent heights measured by $240 \mathrm{GHz}$ radiometer (235 GHz spectrometer) are shown in Figure 14 . Since the FOV of $240 \mathrm{GHz}$ radiometer is $3.3 \mathrm{~km}$, the impact of the antenna is relatively small compared with $118 \mathrm{GHz}$ and $190 \mathrm{GHz}$.

The difference mainly exists in the spectral line wings of $\mathrm{O}_{3}$ at the tangent height of $10 \mathrm{~km}$. The largest brightness temperature offset can be $6 \mathrm{~K}$. Above $50 \mathrm{~km}$, the effect can be neglected. 

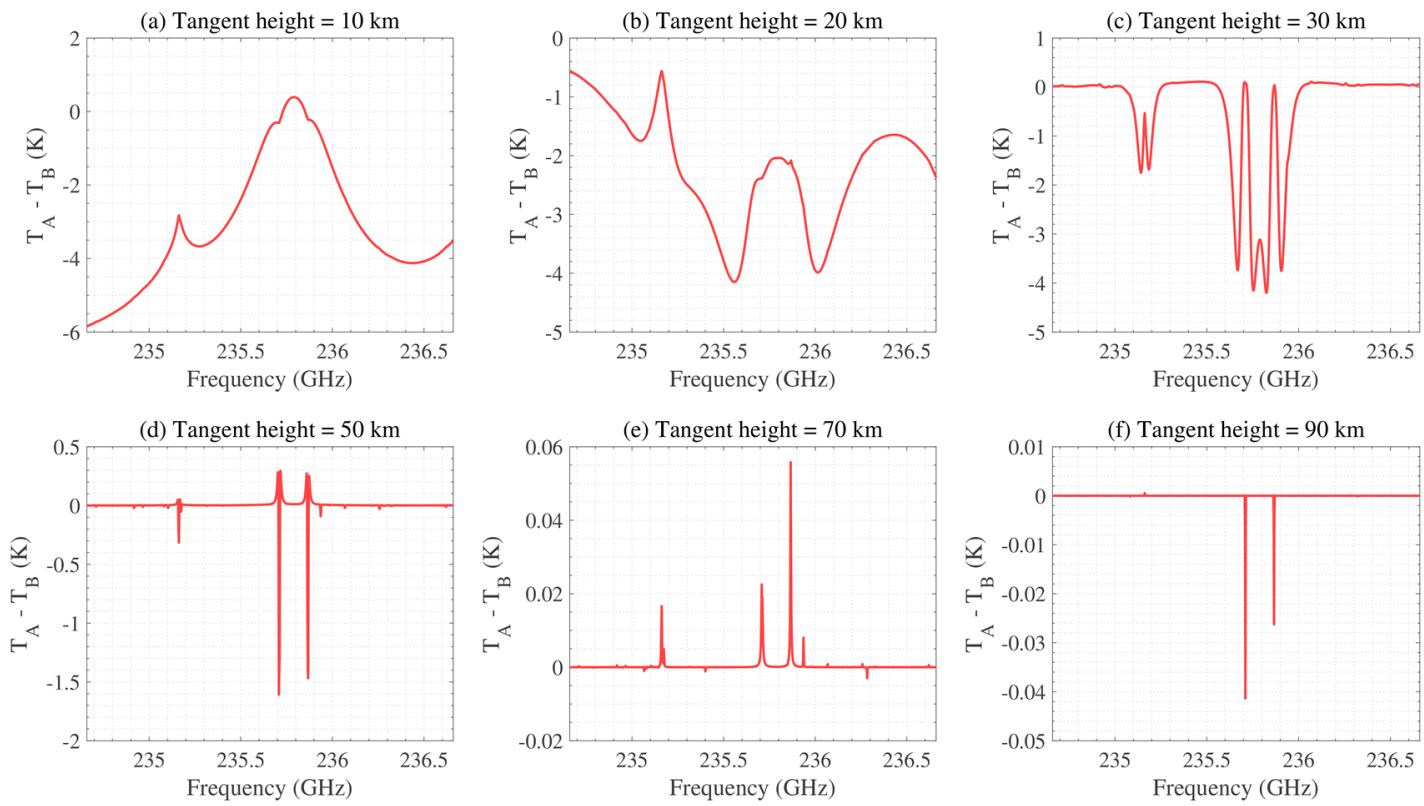

Figure 14. The brightness temperature difference $T_{A}-T_{B}$ at various tangent height measured by $240 \mathrm{GHz}$ radiometer (235 GHz spectrometer): (a) $10 \mathrm{~km}$; (b) $20 \mathrm{~km}$; (c) $30 \mathrm{~km}$; (d) $50 \mathrm{~km}$; (e) $70 \mathrm{~km}$; (f) $90 \mathrm{~km}$.

Figure 15 shows the $\mathrm{O}_{3}$ retrieval errors induced by different calibration uncertainties. R-J approximation is the largest calibration error source which leads to a retrieval error of around $10 \%$ below $70 \mathrm{~km}$. The effect of the antenna pattern is similar to the $190 \mathrm{GHz}$ radiometer, which leads to an error of around $2 \%$ above $20 \mathrm{~km}$ and becomes larger than $10 \%$ below. The residual nonlinearity has a little impact on the retrieval below $70 \mathrm{~km}$, but leads to an error of $5 \%$ above $70 \mathrm{~km}$. The hot target offset causes an error of less than $1 \%$ in the valid observation region.
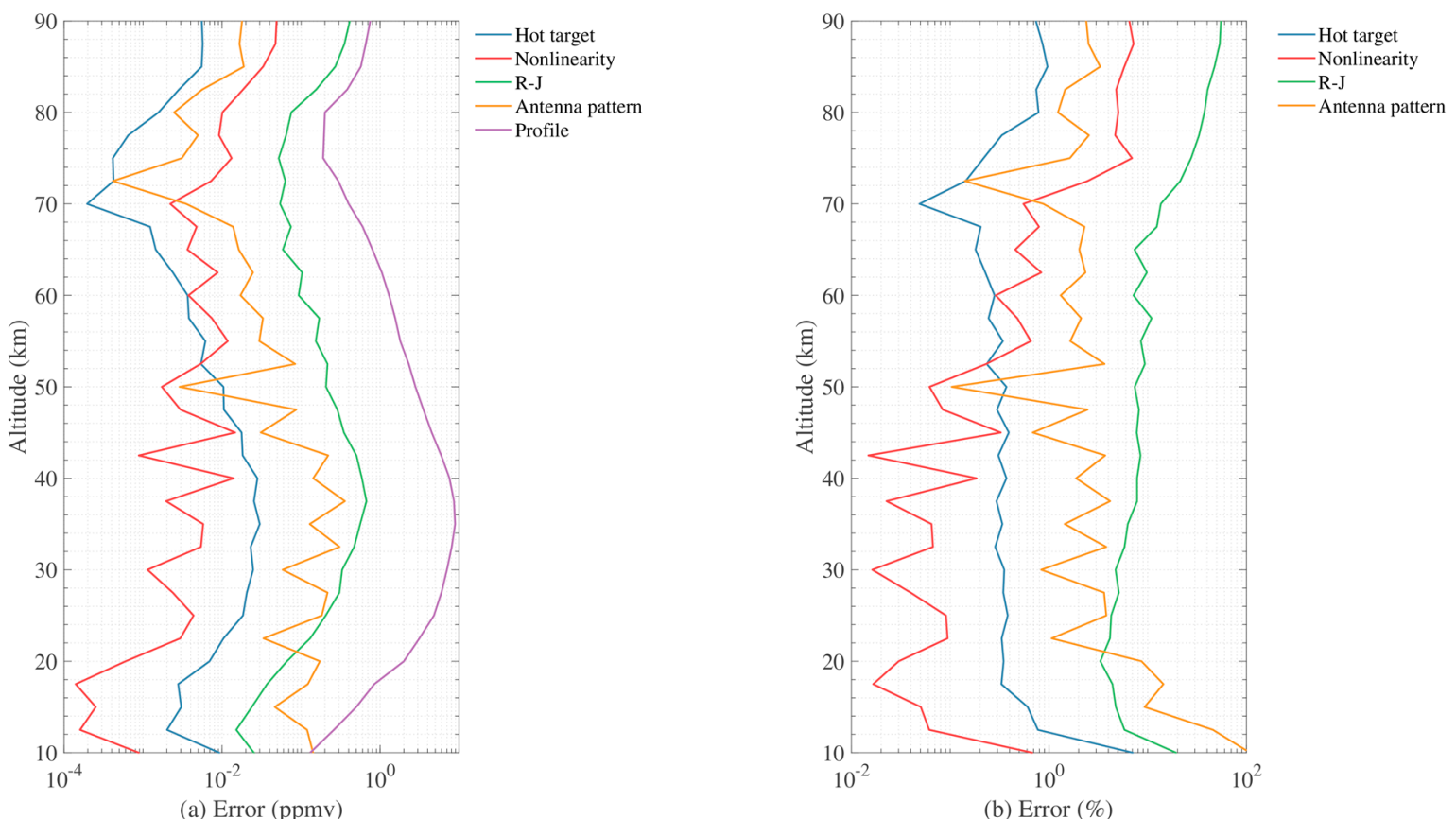

Figure 15. The $\mathrm{O}_{3}$ retrieval errors induced by different calibration error sources: (a) absolute and (b) relative retrieval errors. The uncertainties assumed are summarized in Table 4.

The $\mathrm{O}_{3}$ retrieval errors induced by the a priori errors are shown in Figure 16. The retrieval errors induced by the error of the a priori profile can be neglected below $80 \mathrm{~km}$. 

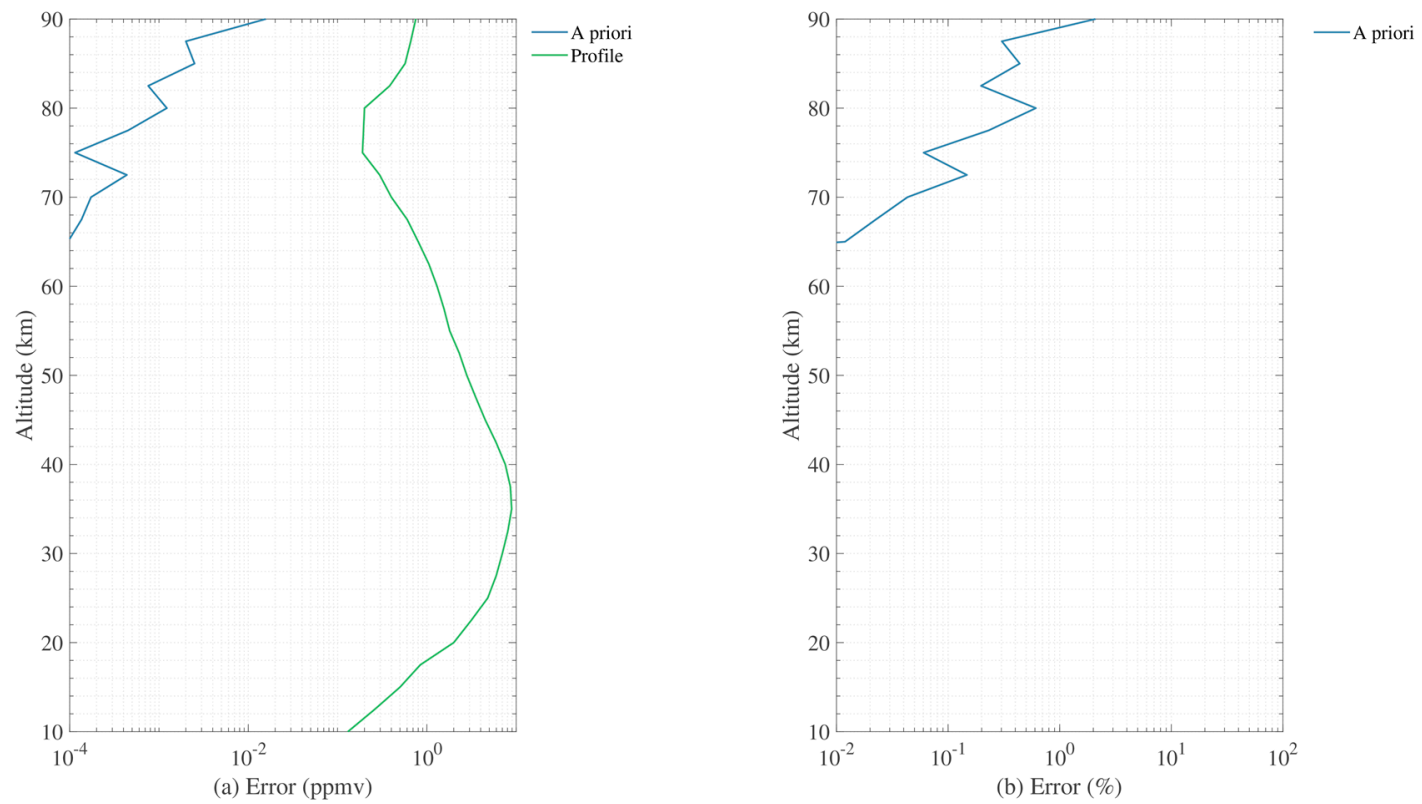

Figure 16. The $\mathrm{O}_{3}$ retrieval error induced by external error source: (a) absolute and (b) relative retrieval errors. The uncertainties assumed are summarized in Table 5.

\section{4. $643 \mathrm{GHz}$}

The $\mathrm{HCl}$ retrieval errors induced by various instrument uncertainties are shown in Figure 17. NEDT is the major error source which leads to an error of less than $20 \%$ below $60 \mathrm{~km}$ and $20 \%-60 \%$ above. The local oscillator offset (LO) causes an error of $1 \%-10 \%$ above $50 \mathrm{~km}$, which is similar to other radiometers. The effect of sideband weight is around $0.5 \%$, which is relatively small. The effect of pointing offset (LOS) can be neglected above $20 \mathrm{~km}$, but becomes large suddenly in the troposphere, since the measurement response in this region is small.
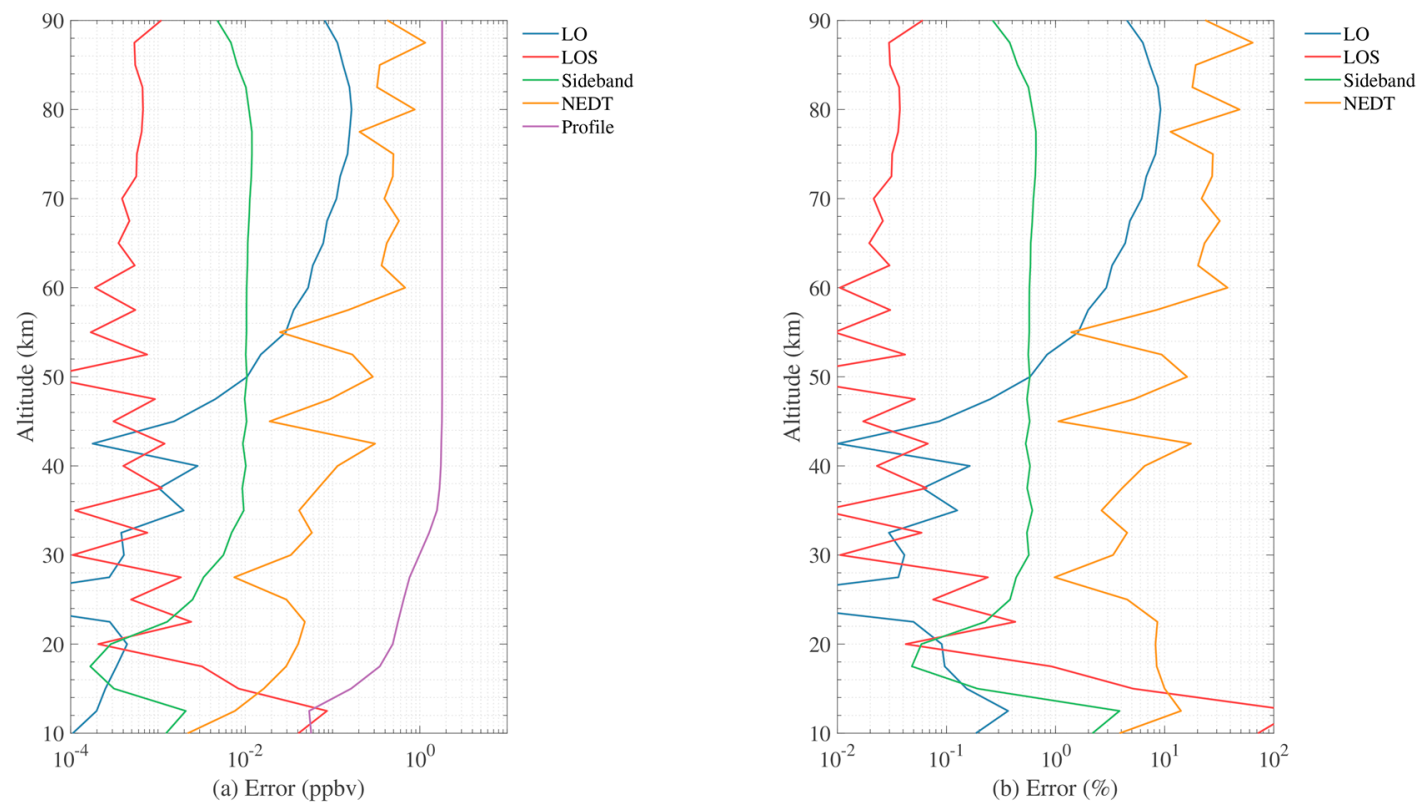

Figure 17. The $\mathrm{HCl}$ retrieval errors induced by different instrument uncertainty sources: (a) absolute and (b) relative retrieval errors. The uncertainties assumed are summarized in Table 3.

The brightness temperature difference $T_{A}-T_{B}$ at various tangent heights measured by $643 \mathrm{GHz}$ radiometer (625 GHz spectrometer) are shown in Figure 18. Since the FOV of $643 \mathrm{GHz}$ radiometer 
is $0.9 \mathrm{~km}$, the antenna pattern only has a little impact on the observation. The largest brightness temperature offset is $0.6 \mathrm{~K}$.
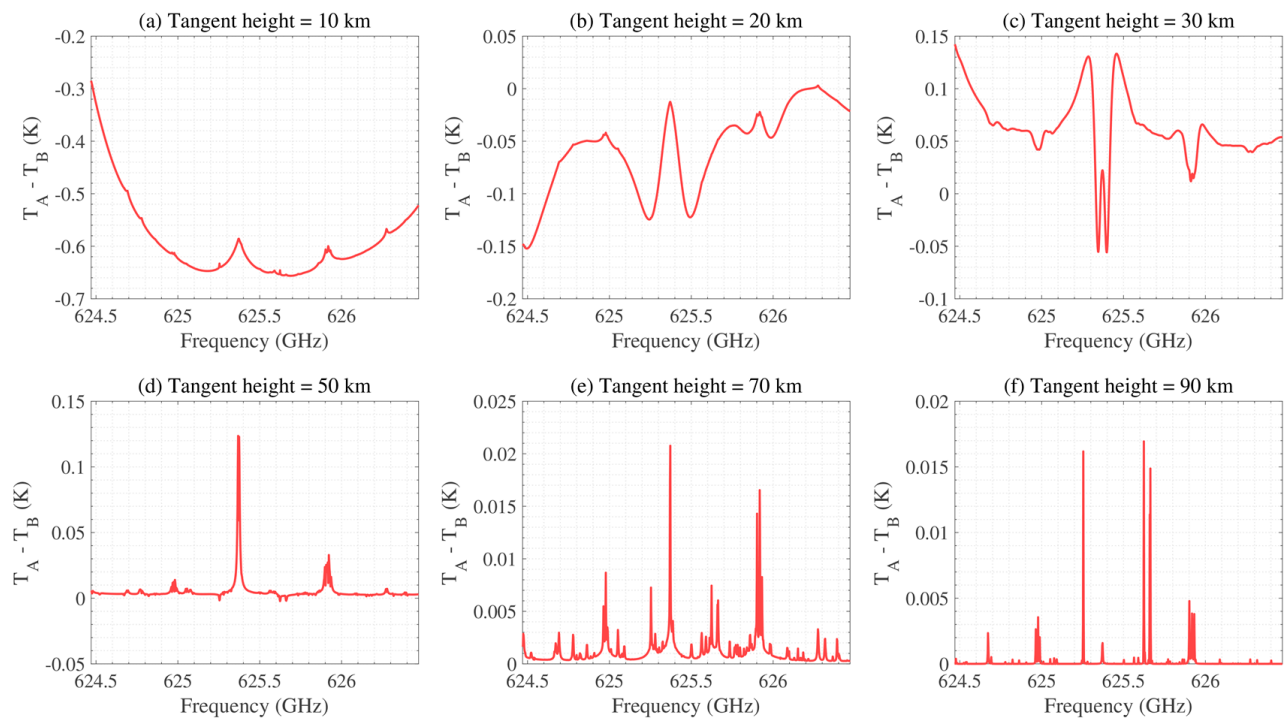

Figure 18. The brightness temperature difference $-T_{B}$ at various tangent height measured by $643 \mathrm{GHz}$ radiometer (625 GHz spectrometer): (a) $10 \mathrm{~km}$; (b) $20 \mathrm{~km}$; (c) $30 \mathrm{~km}$; (d) $50 \mathrm{~km}$; (e) $70 \mathrm{~km}$; (f) $90 \mathrm{~km}$.

Figure 19 shows the $\mathrm{HCl}$ retrieval errors induced by different calibration uncertainties. The retrieval error induced by the R-J approximation is very large because the brightness temperature calculated by the Planck function and R-J approximation are quite different at this frequency region. The retrieval error can be as large as $100 \%$ in the troposphere and mesosphere. The effect of the antenna pattern has an error of less than $1 \%$ above $20 \mathrm{~km}$, but becomes very large in the troposphere. The residual nonlinearity of calibration leads to an error of less than $2 \%$. The hot target offset causes an error of less than $1 \%$ above $20 \mathrm{~km}$, but with increasing rapidly in the troposphere. This sudden increase in the troposphere is due to the small measurement response at these altitudes.
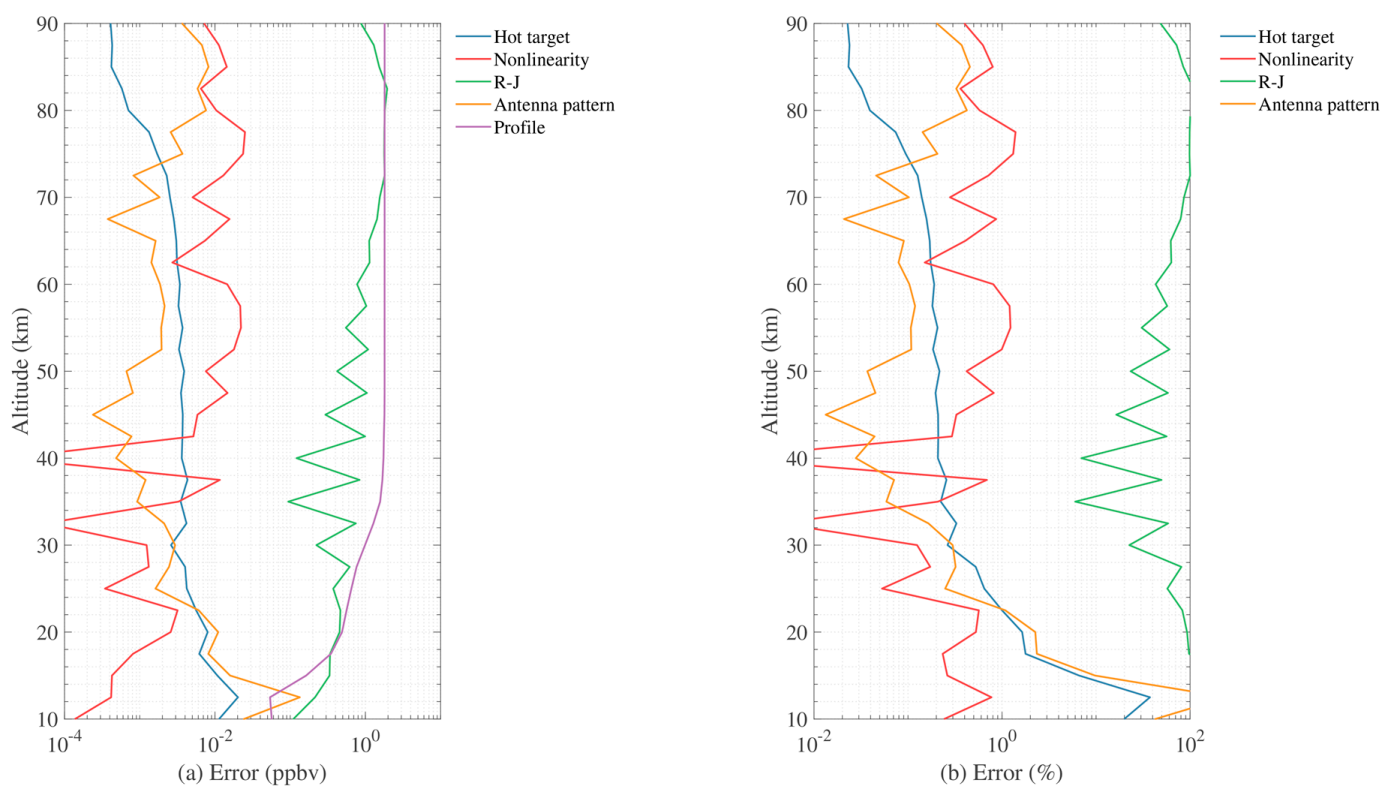

Figure 19. The $\mathrm{HCl}$ retrieval errors induced by different calibration error sources: (a) absolute and (b) relative retrieval errors. The uncertainties assumed are summarized in Table 4. 
The $\mathrm{HCl}$ retrieval error induced by a priori error is shown in Figure 20. The retrieval error induced by a priori profile can be neglected at $20-80 \mathrm{~km}$. However, the error increases in the troposphere and mesosphere due to the measurement information which has lacked.
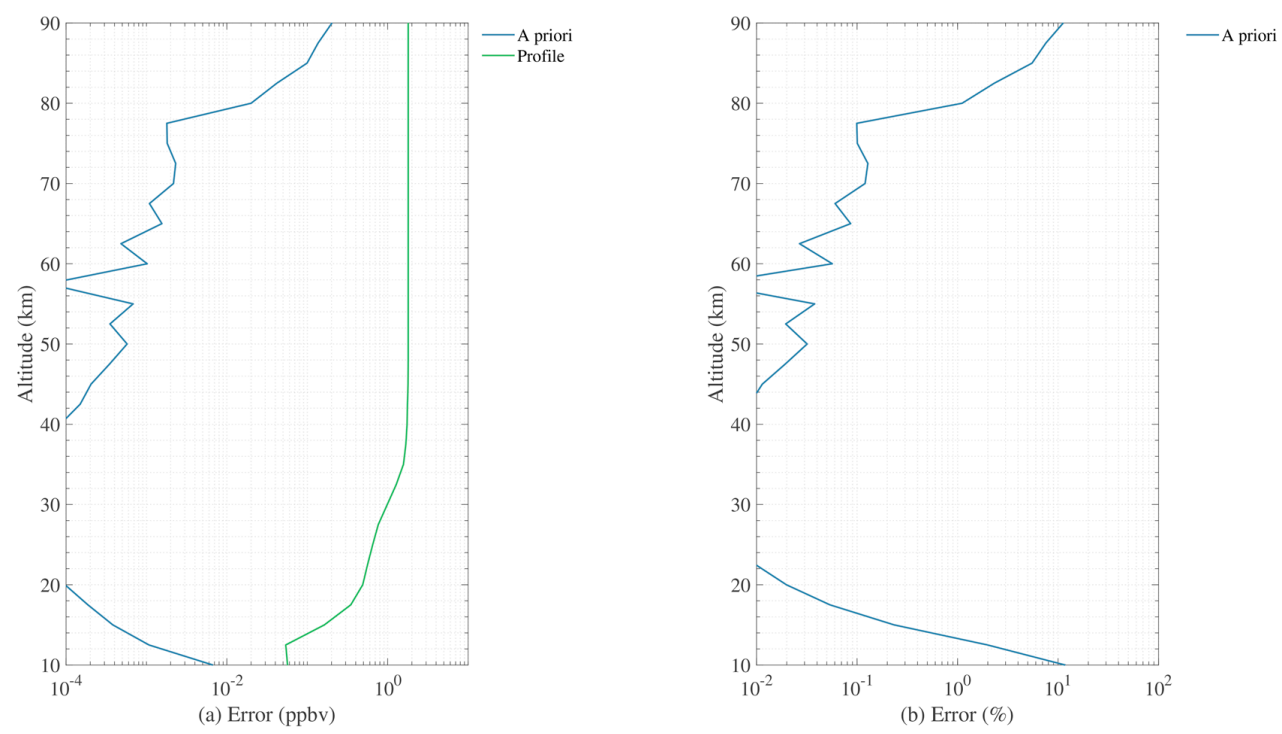

Figure 20. The $\mathrm{HCl}$ retrieval error induced by external error source: (a) absolute and (b) relative retrieval errors. The uncertainties assumed are summarized in Table 5.

\subsection{Overall Error Estimation}

The errors above are simulated independently, keeping the rest of the parameters ideal. The overall error can be calculated by using the sum of the squared errors. R-J approximation is not included, since this error can be avoided by the Planck unit. Figure 21 shows the overall errors of the four radiometers. The errors of temperature are $<3 \mathrm{~K}$ from 27 to $57 \mathrm{~km}$. The instrument uncertainties play the most important role above $45 \mathrm{~km}$, while the calibration errors dominate below.
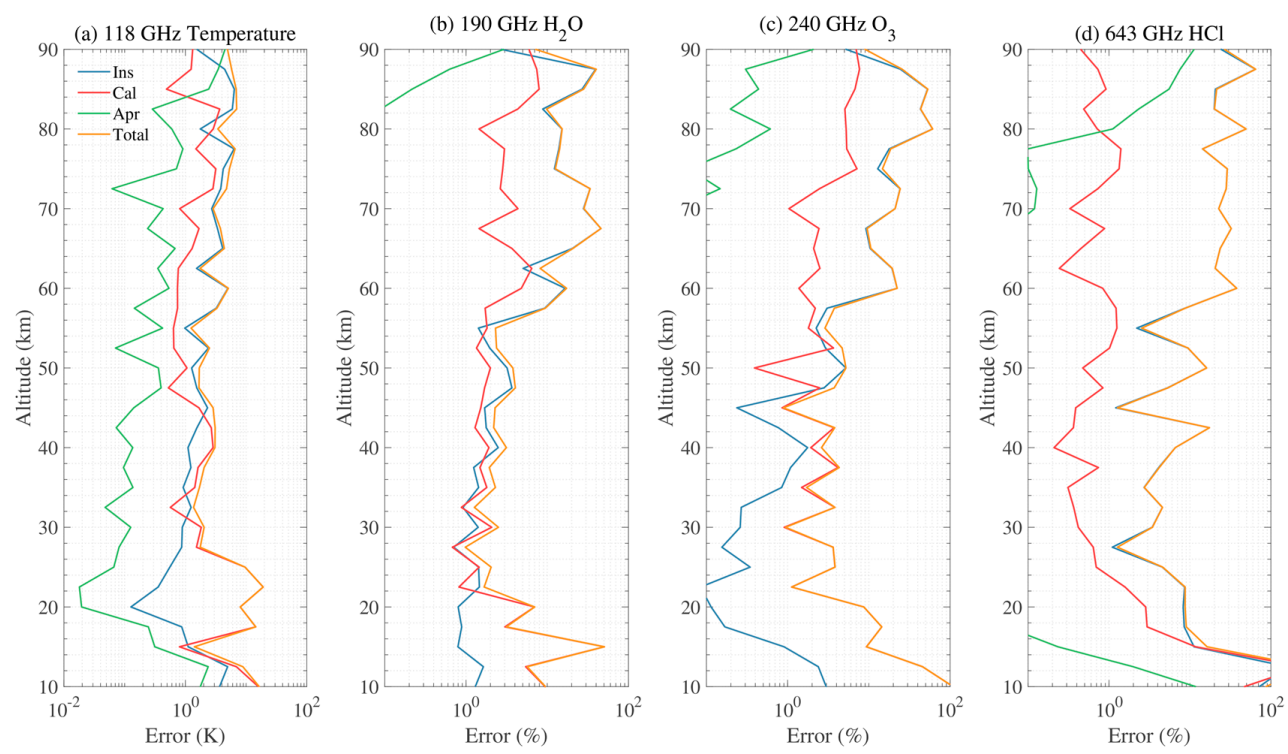

Figure 21. The overall retrieval errors estimation: (a) $118 \mathrm{GHz}$ temperature retrieval; (b) $190 \mathrm{GHz} \mathrm{H}_{2} \mathrm{O}$ retrieval; (c) $240 \mathrm{GHz} \mathrm{O}_{3}$ retrieval; (d) $643 \mathrm{GHz} \mathrm{HCl}$ retrieval. The errors are calculated by using the sum of squared errors. 
The errors of $\mathrm{H}_{2} \mathrm{O}$ are $<10 \%$ from 16 to $58 \mathrm{~km}$. The instrument uncertainties mainly affect the retrieval above $20 \mathrm{~km}$. The errors of $\mathrm{O}_{3}$ are $<10 \%$ from 20 to $58 \mathrm{~km}$, which are similar to that of $\mathrm{H}_{2} \mathrm{O}$. The errors of $\mathrm{HCl}$ are $<20 \%$ from 15 to $59 \mathrm{~km}$ which are controlled by instrument uncertainties, while the calibration errors have little impact.

\section{Conclusions}

The THz Atmospheric Limb Sounder (TALIS) is the first microwave limb sounder being developed in China, and will contribute to atmosphere observation in the future. In this study, the impact of errors on the retrieval induced by three sources including instrument, calibration and external errors, are discussed. Sideband weight, local oscillator offset, measurement noise (NEDT) and pointing angle offset are considered as instrument uncertainties. Calibration errors contain hot target offset, nonlinearity of the two-point calibration, R-J approximation and the antenna pattern. The a priori profiles of temperature, pressure and species are the main external errors, since the model error could not be estimated. It should be noted that simulations from atmospheric profiles under different conditions could have led to different retrieval errors and usable vertical ranges. This simulation only represents a typical atmospheric condition.

Local oscillator offset is quite important in the mesosphere and causes as large as a $5 \mathrm{~K}$ error above $50 \mathrm{~km}$. Retrieval error due to the antenna pattern can be as large as $20 \mathrm{~K}$ in the troposphere, but less than $3 \mathrm{~K}$ at the other altitudes. NEDT, sideband weight and R-J approximation lead to errors of around 1-2 K, respectively. The effect of nonlinearity, hot target offset, pointing offset, pressure and a priori profile are relatively small $(<1 \mathrm{~K})$ in the main observation region.

NEDT is the largest error source in $190 \mathrm{GHz} \mathrm{H} \mathrm{H}_{2} \mathrm{O}$ retrieval which leads to an error of $10 \%-40 \%$ above $60 \mathrm{~km}$. Local oscillator offset causes as large as a 15\% retrieval error at $70 \mathrm{~km}$, but can be neglected below $60 \mathrm{~km}$. R-J approximation is quite important in this frequency band and leads to an error of around $7 \%$. The antenna pattern causes an error of less than $5 \%$, but becomes large in the troposphere. Error due to sideband weight, nonlinearity and hot target offset is less than $1 \%$ in the main region, respectively. The effect of pointing offset and a priori profile is quite small.

The results of $240 \mathrm{GHz} \mathrm{O}$ retrieval are similar to that of $190 \mathrm{GHz}$. Error induced by NEDT dominates the retrieval in the middle and upper atmosphere. It can lead to the largest error of $50 \%$ at $80 \mathrm{~km}$. The error due to R-J approximation is around $10 \%$ below $70 \mathrm{~km}$. The impact of the local oscillator is important above $60 \mathrm{~km}$, and this is around $10 \%$. Hot target and nonlinearity are less than $1 \%$ below $70 \mathrm{~km}$, respectively. The effect of the antenna pattern is similar to that of $190 \mathrm{GHz}$. The effect of sideband weight, pointing offset and a priori can be neglected in the main observation region.

The results of $643 \mathrm{GHz}$ have some difference. R-J approximation becomes the largest error source in $643 \mathrm{GHz} \mathrm{HCl}$ retrieval. An error of $10 \%-100 \%$ is caused by using R-J approximation in calibration. NEDT causes an error of $10 \%-50 \%$ in the middle and upper atmosphere. Retrieval error induced by the local oscillator is $3 \%-10 \%$ above $60 \mathrm{~km}$, which is similar to other radiometers. Errors due to sideband weight, hot target offset and nonlinearity are less than $1 \%$, respectively. Antenna pattern, pointing offset and a priori are quite small in the main observation region, but become large in the troposphere, since the measurement response is small.

From the simulation above, instrument uncertainties are the most important error sources. The calibration residual errors will affect the retrieval in the troposphere and lower stratosphere. R-J approximation should not be used in calibration unless an additional correction can be done. The a priori uncertainties have little influence. Moreover, it is necessary to use an entire antenna pattern in calibration.

Author Contributions: W.W. performed the simulation and analyzed the results; Z.W. and Y.D. analyzed the error sources; W.W. wrote the manuscript; Z.W. edited the article. All authors have read and agreed to the published version of the manuscript.

Funding: This research received no external funding. 
Acknowledgments: The authors would like to thank the ARTS and Qpack development teams for assistance configuring and running the model.

Conflicts of Interest: The authors declare no conflict of interest. The founding sponsors had no role in the design of the study, nor in the collection, analyses, or interpretation of data, as well as no influence in the writing of the manuscript, nor in the decision to publish the results.

\section{References}

1. Schwartz, M.J.; Lambert, A.; Manney, G.L.; Read, W.G.; Livesey, N.J.; Froidevaux, L.; Ao, C.O.; Bernath, P.F.; Boone, C.D.; Cofield, R.E.; et al. Validation of the Aura Microwave Limb Sounder temperature and geopotential height measurements. J. Geophys. Res. Atmos 2008, 113, D15S11. [CrossRef]

2. Waters, J.W.; Froidevaux, L.; Read, W.G.; Manney, G.L.; Elson, L.S.; Flower, D.A.; Jarnot, R.F.; Harwood, R.S. Stratospheric $\mathrm{ClO}$ and ozone from the Microwave Limb Sounder on the Upper Atmosphere Research Satellite. Nature 1993, 362, 597-602. [CrossRef]

3. Barath, F.T.; Chavez, M.C.; Cofield, R.E.; Flower, D.A.; Frerking, M.A.; Gram, M.B.; Harris, W.M.; Holden, J.R.; Jarnot, R.F.; Kloezeman, W.G.; et al. The Upper Atmosphere Research Satellite microwave limb sounder instrument. J. Geophys. Res. Atmos. 1993, 98, 10751-10762. [CrossRef]

4. Waters, J.W.; Read, W.G.; Froidevaux, L.; Jarnot, R.F.; Cofield, R.E.; Flower, D.A.; Lau, G.K.; Pickett, H.M.; Santee, M.L.; Wu, D.L.; et al. The UARS and EOS microwave limb sounder experiments. J. Atmos. Sci. 1999, 56, 194-218. [CrossRef]

5. Murtagh, D.; Frisk, U.; Merino, F.; Ridal, M.; Jonsson, A.; Stegman, J.; Witt, G.; Eriksson, P.; Jimenez, C.; Mégie, G.; et al. An overview of the Odin atmospheric mission. Can. J. Phys. 2002, 80, 309-319. [CrossRef]

6. Urban, J.; Lautié, N.; Le Flochmoën, E.; Jiménez, C.; Eriksson, P.; de la Nöe, J.; Dupuy, E.; Ekström, M.; El Amraoui, L.; Frisk, U.; et al. Odin/SMR limb observations of stratospheric trace gases: Level 2 processing of $\mathrm{ClO}, \mathrm{N} 2 \mathrm{O}, \mathrm{HNO} 3$, and O3. J. Geophys. Res. Atmos. 2005, 110, D14307. [CrossRef]

7. Eriksson, P.; Ekström, M.; Rydberg, B.; Murtagh, D.P. First Odin sub-mm retrievals in the tropical upper troposphere: Ice cloud properties. Atmos. Chem. Phys. 2007, 7, 471-483. [CrossRef]

8. Frisk, U.; Hagström, M.; Ala-Laurinaho, J.; Andersson, S.; Berges, J.-C.; Chabaud, J.-P.; Dahlgren, M.; Emrich, A.; Florén, H.-G.; Florin, G.; et al. The Odin satellite - I. Radiometer design and test. Astron. Astrophys. 2003, 402, L27-L34. [CrossRef]

9. Schoeberl, M.R.; Douglass, A.R.; Hilsenrath, E.; Bhartia, P.K.; Beer, R.; Waters, J.W.; Gunson, M.R.; Froidevaux, L.; Gille, J.C.; Barnett, J.J.; et al. Overview of the EOS Aura Mission. IEEE Trans. Geosci. Remote Sens. 2006, 4, 1066-1074. [CrossRef]

10. Waters, J.W.; Froidevaux, L.; Jarnot, R.F.; Read, W.G.; Pickett, H.M.; Harwood, R.S.; Cofield, R.E.; Filipiak, M.J.; Flower, D.A.; Livesey, N.J.; et al. An Overview of the EOS MLS Experiment, Version 2.0; JPL D-15745/CL\# 04-2323; Jet Propulsion Laboratory, California Institute of Technology: Pasadena, CA, USA, 2004.

11. Waters, J.W.; Froidevaux, L.; Harwood, R.S.; Jarnot, R.F.; Pickett, H.M.; Read, W.G.; Siegel, P.H.; Cofield, R.E.; Filipiak, M.J.; Flower, D.A.; et al. The Earth Observing System Microwave Limb Sounder (EOS MLS) on the Aura Satellite. IEEE Trans. Geosci. Remote Sens. 2006, 44, 1075-1092. [CrossRef]

12. Wu, D.L.; Schwartz, M.J.; Waters, J.W.; Limpasuvan, V.; Wu, Q.; Killeen, T.L. Mesospheric doppler wind measurements from Aura Microwave Limb Sounder (MLS). Adv. Space Res. 2008, 42, 1246-1252. [CrossRef]

13. Livesey, N.J.; Logan, J.A.; Santee, M.L.; Waters, J.W.; Doherty, R.M.; Read, W.G.; Froidevaux, L.; Jiang, J.H. Interrelated variations of $\mathrm{O} 3, \mathrm{CO}$ and deep convection in the tropical/subtropical upper troposphere observed by the Aura Microwave Limb Sounder (MLS) during 2004-2011. Atmos. Chem. Phys. 2013, 13, 579-598. [CrossRef]

14. Wu, D.L.; Jiang, J.H.; Davis, C.P. EOS MLS cloud ice measurements and cloudy-sky radiative transfer model. IEEE Trans. Geosci. Remote Sens. 2006, 44, 1156-1165. [CrossRef]

15. Kikuchi, K.; Nishibori, T.; Ochiai, S.; Ozeki, H.; Irimajiri, Y.; Kasai, Y.; Koike, M.; Manabe, T.; Mizukoshi, K.; Murayama, Y.; et al. Overview and early results of the Superconducting Submillimeter-Wave Limb-Emission Sounder (SMILES). J. Geophys. Res. Atmos. 2010, 115, D23306. [CrossRef]

16. Takahashi, C.; Ochiai, S.; Suzuki, M. Operational retrieval algorithms for JEM/SMILES level 2 data processing system. J. Quant. Spectrosc. Ra. 2010, 111, 160-173. [CrossRef] 
17. Baron, P.; Urban, J.; Sagawa, H.; Möller, J.; Murtagh, D.P.; Mendrok, J.; Dupuy, E.; Sato, T.O.; Ochiai, S.; Suzuki, K.; et al. The Level 2 research product algorithms for the Superconducting Submillimeter-Wave Limb-Emission Sounder (SMILES). Atmos. Meas. Tech. 2011, 4, 2105-2124. [CrossRef]

18. Takahashi, C.; Suzuki, M.; Mitsuda, C.; Ochiai, S.; Manago, N.; Hayashi, H.; Iwata, Y.; Imai, K.; Sano, T.; Takayanagi, M.; et al. Capability for ozone high-precision retrieval on JEM/SMILES observation. Adv. Space Res. 2011, 48, 1076-1085. [CrossRef]

19. Baron, P.; Murtagh, D.P.; Urban, J.; Sagawa, H.; Ochiai, S.; Kasai, Y.; Kikuchi, K.; Khosrawi, F.; Körnich, H.; Mizobuchi, S.; et al. Observation of horizontal winds in the middle-atmosphere between $30^{\circ} \mathrm{S}$ and $55^{\circ} \mathrm{N}$ during the northern winter 2009-2010. Atmos. Chem. Phys. 2013, 13, 6049-6064. [CrossRef]

20. Jiang, J.H.; Su, H.; Zhai, C.X.; Shen, T.J.; Wu, T.W.; Zhang, J.; Cole, J.N.S.; Salzen, K.V.; Donner, L.J.; Seman, C.; et al. Evaluating the Diurnal Cycle of Upper-Tropospheric Ice Clouds in Climate Models Using SMILES Observations. J. Atmos. Sci. 2015, 72, 1022-1044. [CrossRef]

21. Baron, P.; Murtagh, D.; Eriksson, P.; Mendrok, J.; Ochiai, S.; Pérot, K.; Sagawa, H.; Suzuki, M. Simulation study for the Stratospheric Inferred Winds (SIW) sub-millimeter limb sounder. Atmos. Meas. Tech. 2018, 11, 4545-4566. [CrossRef]

22. Ochiai, S.; Baron, P.; Nishibori, T.; Irimajiri, Y.; Uzawa, Y.; Manabe, T.; Maezawa, H.; Mizuno, A.; Nagahama, T.; Sagawa, H.; et al. SMILES-2 Mission for Temperature, Wind, and Composition in the Whole Atmosphere. SOLA 2017, 13A, 13-18. [CrossRef]

23. Baron, P.; Ochiai, S.; Dupuy, E.; Larsson, R.; Liu, H.X.; Manago, N.; Murtagh, D.; Oyama, S.; Sagawa, H.; Saito, A.; et al. Potential for the measurement of MLT wind, temperature, density and geomagnetic field with Superconducting Submillimeter-Wave Limb-Emission Sounder-2 (SMILES-2). Atmos. Meas. Tech. Discuss. 2019. in review.

24. Wang, W.Y.; Wang, Z.Z. Performance Evaluation of THz Atmospheric Limb Sounder (TALIS) of China. Atmos. Meas. Technol. 2020, 13, 13-38. [CrossRef]

25. Verdes, C.; Bühler, S.; von Engeln, A.; Kuhn, T.; Künzi, K.; Eriksson, P.; Sinnhuber, B.M. Pointing and temperature retrieval from millimeter-submillimeter limb soundings. J. Geophys. Res. Atmos. 2002, 107, ACH 10-1-ACH 10-24. [CrossRef]

26. Eriksson, P.; Ekström, M.; Melsheimer, C.; Buehler, S.A. Efficient forward modelling by matrix representation of sensor responses. Int. J. Remote Sens. 2006, 27, 1793-1808. [CrossRef]

27. Jarnot, R.F.; Perun, V.S.; Schwartz, M.J. Radiometric and Spectral Performance and Calibration of the GHz Bands of EOS MLS. IEEE Trans. Geosci. Remote Sens. 2006, 44, 1131-1143. [CrossRef]

28. Ochiai, S.; Kikuchi, K.; Nishibori, T.; Manabe, T. Gain Nonlinearity Calibration of Submillimeter Radiometer for JEM/SMILES. IEEE J. Sel. Top. Appl. Earth Observ. Remote Sens. 2012, 5, 962-969. [CrossRef]

29. Wang, Z.Z.; Li, J.Y.; He, J.Y.; Zhang, S.W.; Gu, S.Y.; Li, Y.; Guo, Y.; He, B.Y. Performance Analysis of Microwave Humidity and Temperature Sounder Onboard the FY-3D Satellite from Prelaunch Multiangle Calibration Data in Thermal/Vacuum Test. IEEE Trans. Geosci. Remote Sens. 2019, 57, 1664-1683. [CrossRef]

30. Weng, F.Z.; Zou, X.L. Errors from Rayleigh-Jeans approximation in satellite microwave radiometer calibration systems. Appl. Optics 2013, 52, 505-508. [CrossRef]

31. Jarnot, R.F.; Cofield, R.E.; Waters, W.G.; Flower, D.A. Calibration of the Microwave Limb Sounder on the Upper Atmosphere Research Satellite. J. Geophys. Res. Atmos. 1996, 101, 9957-9982. [CrossRef]

32. Cofield, R.E.; Stek, P.C. Design and Field-of-View Calibration of 114-660-GHz Optics of the Earth Observing System Microwave Limb Sounder. IEEE Trans. Geosci. Remote Sens. 2006, 44, 1166-1181. [CrossRef]

33. Rydberg, B.; Eriksson, P.; Kiviranta, J.; Ringsby, J.; Skyman, A.; Murtagh, D. Odin/SMR Algorithm Theoretical Basis Document: Level 1 Processing. Tech.; Department of Space, Earth and Environment, Chalmers University of Technology: Goteborg, Sweden, 2017.

34. Rodgers, C.D. Inverse Methods for Atmospheric Sounding: Theory and Practice. World Scientific: Singapore, 2000; pp. 81-99. Available online: https://books.google.com.hk/books?hl=en\& lr=\&id=FjxqDQAAQBAJ\&oi=fnd\&pg=PR7\&dq=Inverse+Methods+for+Atmospheric + Sounding: +Theory+and+Practice\&ots=ARbv5T9AWl\&sig=dHFruTHfErcOkyZChZL7PbGHfgU\&redir_esc=y\&hl= $\mathrm{zh}-\mathrm{CN} \&$ sourceid $=\mathrm{cndr} \# \mathrm{v}=$ onepage\&q=Inverse $\% 20$ Methods $\% 20$ for $\% 20 \mathrm{Atmospheric} \% 20$ Sounding $\% 3 \mathrm{~A} \%$ 20Theory\%20and\%20Practice\&f=false (accessed on 10 December 2019).

35. Livesey, N.J.; Snyder, W.V.; Read, W.G.; Wagner, P.A. Retrieval Algorithms for the EOS Microwave Limb Sounder (MLS). IEEE Trans. Geosci. Remote Sens. 2006, 44, 1144-1155. [CrossRef] 
36. Erikson, P.; Chen, D. Statistical parameters derived from ozonesonde data of importance for passive remote sensing observations of ozone. Int. J. Remote. Sens. 2002, 23, 4945-4963. [CrossRef]

37. Rodgers, C.D. Characterization and error analysis of profilesretrieved from remote sounding measurements. J. Geophys. Res. 1990, 95, 5587-5595. [CrossRef]

38. Eriksson, P.; Buehler, S.A.; Davis, C.P.; Emde, C.; Lemke, O. ARTS, the atmospheric radiative transfer simulator, Version 2. J. Quant. Spectrosc. Ra. 2011, 112, 1551-1558. [CrossRef]

39. Eriksson, P.; Jiménez, C.; Buehler, S.A. Qpack, a general tool for instrument simulation and retrieval work. J. Quant. Spectrosc. Ra. 2005, 91, 47-64. [CrossRef]

(C) 2020 by the authors. Licensee MDPI, Basel, Switzerland. This article is an open access article distributed under the terms and conditions of the Creative Commons Attribution (CC BY) license (http://creativecommons.org/licenses/by/4.0/). 